PNL-2545

UC-60

\title{
Annual Report of the Wind Characteristics Program Element for the Period July 1977 Through July 1978
}
L. L. Wendell
J. R. Connell
W. T. Pennell
D. S. Renne
H. L. Wegley

December 1978

Prepared for the U.S. Department of Energy under Contract EY-76-C-06-1830

Pacific Northwest Laboratory Operated for the U.S. Department of Energy by Battelle Memorial Institute 


\title{
NOTICE
}

This report was prepared as an account of work sponsored by the United States Government. Neither the United States nor the Department of Energy, nor any of their employees, nor any of their contractors, subcontractors, or their employees, makes any warranty, express or implied, or assumes any legal liability or responsibility for the accuracy, completeness or usefulness of any information, apparatus, product or process disclosed, or represents that its use would not infringe privately owned rights.

The views, opinions and conclusions contained in this report are those of the contractor and do not necessarily represent those of the United States Government or the United States Department of Energy.

\author{
PACIFIC NORTHWEST LABORATORY \\ operated by \\ BATTELLE \\ for the \\ UNITED STATES DEPARTMENT OF ENERGY \\ Under Contract EY-76-C-06-1830
}

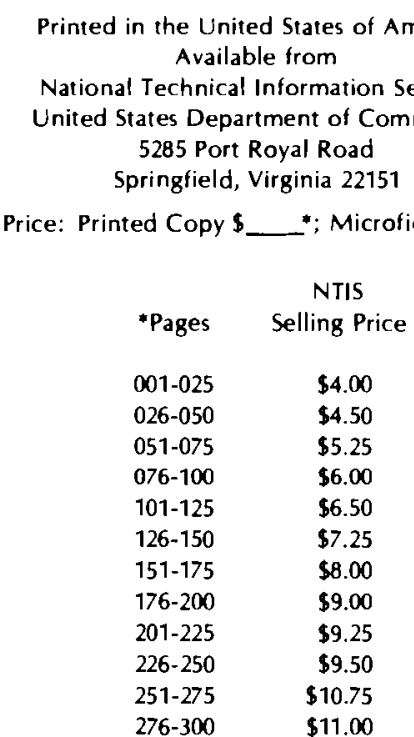


ANNUAL REPORT OF THE

WIND CHARACTERISTICS PROGRAM

ELEMENT FOR THE PERIOD

JULY 1977 THROUGH JULY 1978

L. L. Wendel1

J. R. Connel1

W. T. Pennell

D. S. Renne

H. L. Wegley

December 1978

Prepared for

the U.S. Department of Energy

under Contract EY-76-C-06-1830

PACIFIC NORTHWEST LABORATORY

Richland, Washington 99352 


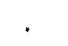

-

- 


\section{SUMMARY}

As a service element within the Federal Wind Energy Prograil, the Wind Characteristics Program Element (WCPE) is established to provide the appropriate wind characterisitcs information to those involved in the design and evaluation of wind energy conversion systems (WECS), in energy program planning, in selecting sites for WECS installation, and in the operation of WECS. To effectively produce the information needed in these four categories, the WCPE, for which Pacific Northwest Laboratory (PNL) has the responsibility for management and technical assistance, has been divided into four technical program areas.

This annual report to the Wind Systems Branch (WSB) of the Department of Energy's (DOE's) Division of Distributed Solar Technology describes the technical progress within each program area from July 1977 through July 1978. This report includes the progress accomplished directly by PNL, by other DOE laboratories (Lawrence Livermore Laboratory and Sandia Laboratories), and by contractors funded directly by DOE or through PNL.

The goal of Wind Characteristics for Design and Performance Program area is to provide descriptions of the wind environment that a WECS might experience. Some of the significant activities and accomplishments for the current reporting period are:

- A report entitled Wind Velocity-Change (Gust-Rise) Criteria for Wind Turbine Design was completed and published. A follow-on report on wind direction change is in preparation.

- Other gust analyses have also been completed for publication and verification with the data from a circular array of anemometers. 
- An analysis of turbulent fluctuations in the wind data from the same array of anemometers indicated limited possibility of predicting these fluctuations with greater accuracy than those predicted, based on persistence.

- Initial analyses from the 24.4-m circular array of anemometers have been published and indicate a sharp contrast between the wind sensed by the rotating blade of a horizontal axis turbine and an anemometer at hub height. These data tapes have been made available to wind turbine designers. Wind data are also being collected from a 49-m circular array of anemometers for use by large wind turbine designers.

The Mesoscale Wind Characteristics Program area has two main goals: to test and apply techniques for analyzing the wind-energy potential over large areas and to analyze the windenergy potential at specified locations, e.g., at sites that are candidates for testing and demonstrating wind machines. Some major activities for the current reporting period are:

- The development of prototype techniques for screening all available data over a large region and for incorporating these data into a large-area analysis have been completed.

- Applications of these techniques to five states in the northwestern United States have begun. This task is to be completed during the next reporting period and included in reports on the techniques and windenergy potential of the Northwest. Application of this type of analysis is planned for other sections of the United States.

- The use of LANDSAT satellite imagery to locate areas that have landforms indicating strong winds has been 
shown to provide valuable qualitative information where conventional wind measurements are not available.

- The analysis and presentation of candidate site wind data were modified to facilitate interpretation of the data by the site Review Board.

The Development of Siting Methodologies Program area has three main goals: to devise strategies for selecting specific sites for WECS installation, to develop tools to implement these strategies, and to supply the appropriate siting methodologies to those who need them. Some of the major accomplishments in this program area are:

- A Siting Handbook for Small wind Energy Conversion Systems was completed and published. The document will be updated according to review comments received and will be republished for wider distribution.

- Useful relationships have been established between mean annual wind speed and two indicators of tree shape for conifers.

- The very good agreement between field measurements and wind tunnel measurements for flow through a gorge indicates the value of physical modeling for examining the flow over small sections of terrain.

The Wind Characteristics for WECS Operations Program area has two major goals: to identify specific wind-forecasting needs of potential WECS users and to determine if windforecasting reliability meets these needs. Major activities during this reporting period are:

- A document entitled Report From a Working Group Meeting on Wind Forecasts for WECS Operations was published. The reported results indicate that wind forecasts of the type needed by the utility community are not operationally available for evaluation. 
A request for proposals was issued to solicit contractors to use available methods to produce 24-hr wind forecasts for a historical data period of one year for three specified locations. The forecast winds will be evaluated in a follow-on effort to determine the reliability of the current state of operational forecasting. 
SUMMARY . . . . . . . . . . . . . . . . . . .

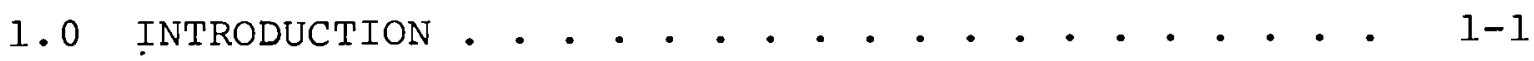

2.0 WIND CHARACTERISTICS FOR DESIGN AND PERFORMANCE

EVALUATIONS. . . . . . . . . . . . . . . . . 2-1

2.1 PROGRESS IN TECHNICAL TASKS . . . . . . . 2-3

2.1.1 Environmental Design Criteria for

WECS. . . . . . . . . . . 2-3

2.1.2 Error Band Analysis on Conventional

Data. . . . . . . . . . . 2-6

2.1.3 Flow Through a Vertical Plane . . . 2-8

2.1.4 Flow Through a Vertical Plane:

Supplementary Gauss-Markov Analysis . 2-10

2.1.5 Meteorological Instrumentation and

Data Analysis Requirements for

Performance Evaluation. . . . . 2-12

3.0 MESOSCALE WIND CHARACTERISTICS . . . . . . . . . 3-1

3.1 PROGRESS IN TECHNICAL TASKS . . . . . . . 3-5

3.1.1 Prototype Techniques for Analyzing

the Wind-Energy Potential Over Large

Areas . . . . . . . . . 3-5

3.1.2 MOD-OA and MOD-1 Candidate site

Meteorological Documentation. . . 3-11

3.1.3 Identification and Meteorological

Documentation of Potential Sites

for Testing Large Turbines and Wind

Turbine "Farms". . . . . . . . . 3-14

3.1.4 Techniques for Estimating wind

Characteristics at Potential Wind

Energy Conversion Sites . . . . . 3-16

3.1.5 Evaluation and Implementation of

Wind Prediction Techniques at

Potential Sites.. . . . . . . 3-21

3.1.6 Locating High Nind Areas by Remote Observations of Eolian Features. . 3-24

3.1.7 Innovative Techniques for Locating and Evaluating High Wind Areas. . 3-30

3.1.7a Innovating Techniques for Locating and Evaluating High Wind Areas. . . 3-32 
3.1.8 Survey Methodology and Reliability

Analysis for Site wind

Characteristics. . . . . . . 3-34

3.1.9 Meteorological studies for wind

Power. . . . . . . . . . 3-37

3.1.10 Energy Statistics for Large wind Turbine Arrays . . . . . . . . 3-40

3.1.11 Mesoscale Wind Characteristics in Mountainous Terrain. . . . . . 3-44

3.1.12 Coastal Zone Wind Energy . . . . . 3-46

3.1.13 Alaskan Wind Power Study . . . . . 3-52

4.0 SitiNG METHODOLOGIES. . . . . . . . . . . . 4-1

4.1 PROGRESS IN TECHNICAL TASKS. . . . . . . . 4-6

4.1.1 Wind Power Studies . . . . . . 4-6

4.1.2 Development of a Wind Energy Site

Selection Methodology. . . . . . 4-8

4.1.3 Sites for Wind Power

Installations. . . . . . . . . 4-13

4.1.4 Vegetation as an Indicator of High $4-19$

4.1.5 Assessing the Local Windfield. . . 4-25

4.1.6 Technique for siting Using

Statistics on Primitive Equation

Model Results. ....... . . 4-26

4.1.7 The Effect of Atmospheric Density

Stratification on Wind-Turbine

Siting . . . . . . . . . . 4-28

4.1.8 Plan Site Screening Technique

Verification and Comparison. . . . 4-30

4.1.9 Wind Turbine Generator Siting

Techniques Relative to Three-

Dimensional Terrain Features . . . 4-32

4.1.10 Revision of Small WECS Handbook. . . 4-35

4.1.11 Update Large System Siting Handbook. 4-37

5.0 WIND CHARACTERISTICS FOR WECS OPERATIONS. . . . . 5-1

5.1 PROGRESS IN TECHNICAL TASKS. . . . . . . . . 5-2

5.1.1 Identification of Needs and

Liaison Activities . . . . . . . 5-2

5.1 .2 Determination of Wind-Forecasting
Uncertainty. . . . . . . . 5-5 
6.0 REFERENCES. . . . . . . . . . . . . . . 6-1

APPENDIX A: PUBLISHED REPORTS GIVEN UC-60

DISTRIBUTION . . . . . . . . . . . $\mathrm{A}-1$ 



\subsection{INTRODUCTION}

The primary objectives of the Federal Wind Energy Program are: to accelerate the development of reliable and economically viable wind energy systems and to enable the earliest possible commercialization of wind power. ${ }^{1}$ Information about wind characteristics that directly affect the reliability and economics of wind energy conversion systems (WECS) is one element of this multifaceted federal program. In April 1976, Pacific Northwest Laboratory (PNL) was assigned the responsibility for management and technical coordination of the wind Characteristics Program Element (WCPE). This Annual Report of the Program Element outlines the technical progress from July 1977 through July 1978.

The primary objective of the WCPE is to provide, through research and development projects, appropriate information about wind characteristics to those involved in the design and evaluation of WECS, in energy program planning, in selecting sites for WECS installations, and in the day-to-day operation of WECS. To more effectively meet these various needs, the WCPE has been divided into the following technical program areas:

- Wind Characteristics for Design and Performance Evaluation

- Mesoscale Wind Characteristics

- Development of Siting Methodologies

- Wind Characteristics for WECS Operations

In spite of the division shown, all the efforts in each program area could not be completely distinct and independent of the efforts in the other areas. Therefore, careful coordination is necessary for efficient and effective use of available funding. A detailed description of the FY-1978 goals and project schedules for each program area are presented in a summary document of the WECS development plan. ${ }^{2}$ The overall goals of each program area are presented below. 
The Wind Characteristics for Design and Performance Evaluation Program area, which is divided into two subareas, is concerned with the direct interaction between meteorological phenomena and a WECS. The design portion of the program area characterizes wind and other meteorological phenomena. Performance evaluation recommends meteorological instrumentation, instrumentation deployment, data collection, and analysis techniques for testing WECS. The WCPE does not intend to design WECS nor to evaluate their performance; however, it does provide meteorological support to those involved in such activities.

The Mesoscale inind Characteristics Program area has two main goals. The first is to develop and present analyses of the wind-energy potential over large areas. These analyses are to identify smaller areas of favorable wind characteristics and to quantify the wind-energy potential over the whole area. The second major goal of this program area is to analyze the windenergy potential at specified locations, e.g., at sites that are candidates for testing and demonstrating wind machines.

The Development of Siting Methodologies Program area is to devise strategies for selecting specific sites for WECS installation, to develop tools to implement these strategies, and to supply this methodology to WECS users. To meet its objectives, this program area has been divided into three sections:

- Site Screening and Localization Technique Development

- Verification of Siting Techniques

- Documentation of siting strategies.

The Wind Characteristics for WECS Operations Program area is a FY-1978 addition to the WCPE. The initial objectives of this program area are to identify specific wind-forecasting needs of potential WECS users and to determine if current windforecasting reliability meets these needs. 
The technical progress covered in this report includes that accomplished directly by PNL, by other Department of Energy (DOE) laboratories (Lawrence Livermore Laboratory and Sandia Laboratories), and by contractors funded directly by DOE or through PNL. Because of the urgency to provide information pertinent to the goals of the Federal Wind Energy Program, highest priority has been given to those projects that answer specific and immediate needs.

The format of this report has been modified slightly from that of previous annual reports. This report is divided into four major parts (Sections 2.0 through 5.0), each corresponding to a program area. Each section includes an overview of the progress in the program area as well as the progress in each individual task within that program area. Each task is identified by letter and number, which corresponds with that in the Summary Development Plan.

Because of the number and diversity of projects in the WCPE, this report is not designed to provide a wealth of technical detail, but rather to provide the reader with sufficient information to lead him to a detailed report (see Appendix A) or to personal contact with those directly involved in the work. In this way, one of the important functions of the WCPE, which is to promote fruitful exchanges of information, may be realized. 



\subsection{WIND CHARACTERISTICS FOR DESIGN AND PERFORMANCE EVALUATIONS}

The goal adopted in this program area is to provide relevant descriptions of the wind environment that a WECS might experience. Accordingly, a series of studies has been undertaken to supply information that may be useful and necessary for design and performance considerations.

Analyses of the number of gusts exceeding a given amplitude have been completed, using a number of different approaches. Estimates have been obtained for the number of times that the wind speed may be expected to change by a given magnitude in a given period of time over various wind turbines (see Task Ala). Comparisons of the predictions of the different approaches are being completed, and these, in turn, will be compared to field observations obtained from a circular array of anemometers. This research is intended to aid in stress and fatigue calculations for WECS design.

A study of turbulence is based on data from this same array of anemometers (see Task Ale). This study analyzed wind fluctuations to determine if characteristic patterns might be present, which would allow short-term predictions of wind speeds to be made. Such information could be useful in various blade control strategies either for reducing stresses or for improving power extraction efficiency. The results of this study indicated that such patterns are not well defined and that attempts to predict winds on this basis are not markedly more successful than predictions simply based on persistence. A larger vertical array of anemometers has been erected and is currently being used to gather additional data for studying the structure of atmospheric turbulence, wind shear, and other meteorological parameters.

Attempts to describe the relationships among various meteorological parameters are frequently complicated by the presence 
of a significant amount of scatter in the data. It is not unusual for different investigators to propose different formulas relating the same quantities. As a result, several literature surveys were conducted, the findings of which have been summarized in terms of some of these parametric relationships (see Task Alb). Among those relationships considered were the dependence of wind-shear power-law exponents on roughness length and stability, the variation of turbulent intensity with roughness length, and the representation of turbulence spectra by various formulas.

A contract has been awarded to Pennsylvania state University to pursue further the problem of representing the variance of turbulent fluctuations in regions of rough terrain. This study is particularly timely in view of the probability of locating WECS in areas that are not level nor homogeneous.

Meteorological instrumentation and methods of data analysis must be developed in order to properly evaluate the performance of WECS. A multiple-bin method of speed magnitude sorting has been used to develop speed distribution statistics. A measurement and analysis program has also been performed, using tower anemometer data, which describes mean wind and turbulence characteristics (see Task A2). 


\subsection{PROGRESS IN TECHNICAL TASKS}

\subsubsection{Environmental Design Criteria For WECS (Ala)}

Pacific Northwest Laboratory

Richland, WA 99352

Principal Investigators:

W. C. Cliff (509) 946-2024

C. H. Huang (509) 942-4121

T. C. Kerrigan

Objective:

To describe, define and provide to DOE/HQ and other elements of FWEP state-of-the-art wind characteristics needed for WECS design.

Program Status:

This effort began in FY-1977 and will continue through FY-1979. A specific effort on gust-rise exceedance statistics began in FY-1978 and will be completed in early FY-1979.

\section{Progress During Reporting Period:}

Three speed-change (gust-rise) models were completed. Two were based on the use of Rice's theorem for level crossings, but differed in the treatment of the high frequency components of the longitudinal velocities. The third approach assumes the existence of a normal probability distribution for speed differences. Methods were developed for computing the root mean square (rms) value of the speed change that a wind turbine rotor system would encounter, the total number of gusts exceeding a given amplitude that would be experienced over a specified period of time, the largest speed difference expected during the life of a turbine, and the risk of exceeding a 
given speed change. An example of changes in speed is given in Table 2-1, which shows the estimated magnitudes of wind speed change expected to occur once every $30 \mathrm{yr}$. The columns of numbers give the expected magnitude as a function of rise time $(\tau)$ and the diameter of the wind turbine. Such information is required for stress and fatigue calculations in the design of WECS.

Expected Progress During Next Reporting Period:

A wind direction change model will be completed and a report on the subject will be issued. A report on gust-rise exceedance statistics will also be completed. A comparison of the three speed-change models will be undertaken.

Reports and Publications:

W. C. Cliff and G. H. Fichtl(a), Wind VelocityChange (Gust Rise) Criteria for wind Turbine Design. PNL-2526, Battelle, Pacific Northwest Laboratories, Richland, WA 99352, July 1978. w. C. Cliff, The Effect of Generalized Wind Characteristics on Annual Power Estimates from Wind Turbine Generators. PNL-2436, Battelle, Pacific Northwest Laboratories, Richland, WA 99352, October 1977.

\footnotetext{
(a) Consultant 3705 College Park Circle Huntsville, AL 35805
} 


\section{TABLE 2-1. Speed Change for 30-yr Recurrence, $\mathrm{m} / \mathrm{sec}$}

\begin{tabular}{c} 
Rise Time \\
$(\tau)$, sec \\
\hline 0.05 \\
0.1 \\
0.3 \\
0.5 \\
1.0 \\
3.0 \\
5.0 \\
10.0
\end{tabular}

\begin{tabular}{|c|c|c|}
\hline $\begin{array}{rr}\text { Small, } & \text { l } \mathrm{m} \\
\Delta \mathrm{v} & \\
\end{array}$ & $\begin{array}{rr}\text { Medium, } 10 \mathrm{~m} \\
\Delta \mathrm{v} & \\
\end{array}$ & $\begin{array}{r}\text { Large, } 60 \mathrm{~m} \\
\Delta \mathrm{v}\end{array}$ \\
\hline 6.4649 & 5.8683 & 3.9203 \\
\hline 8.9253 & 8.3573 & 7.1961 \\
\hline 14.717 & 13.779 & 12.583 \\
\hline 18.379 & 17.241 & 16.126 \\
\hline 24.34 & 22.846 & 21.791 \\
\hline 34.603 & 31.773 & 30.916 \\
\hline 38.274 & 35.405 & 34.289 \\
\hline 40.762 & 38.536 & 36.631 \\
\hline
\end{tabular}


2.1.2 Error Band Analysis on Conventional Data (Alb)

Pacific Northwest Laboratory

Richland, WA 99352

Principal Investigator:

C. H. Huang (509)942-4121

Objective:

To provide a measure of the data spread, variance and/or statistical confidence intervals associated with empirical curve fits to conventional meteorological data.

Program Status:

Initial efforts began in FY-1978. At the end of FY-1978 a decision will be made on whether or not to extend this effort.

Progress During Reporting Period:

Literature describing measured values of some atmospheric variables relevant to WECS design and performance was surveyed. Data of the following types were compared: longitudinal spectra of wind speed, integral length-scale turbulence intensity, surface roughness length, two-point wind-speed correlations, fluctuations of wind direction and power-law wind profiles. Studies that compare the variance among measured values of atmospheric parameters must be conducted in order to assess the errors associated with a relation recommended for use in designing a WECS.

Expected Progress During Next Reporting Period:

A draft report containing summaries and comparisons of the relations reported in the papers surveyed will be written. 
Reports and Publications:

None. 


\subsubsection{Flow Through a Vertical Plane (Ale)}

Pacific Northwest Laboratory

Richland, WA 99352

Principal Investigator:

M. Gary Verholek (509)942-4621

Objective:

To use field measurements to examine and analyze the flow through a vertical plane consistent with a wind environment that a WECS would encounter.

Program Status:

This effort began in FY-1977 and the effort using the 49-m circular array of anemometers will continue through $\mathrm{FY}-1979$.

Progress During Reporting Period:

Initial studies on the original 24.4-m array have been completed, and a report of these preliminary results has been published. Results have indicated 1) that data from the single hub-height anemometer do not adequately describe the windfield structure as synthesized from the anemometers representing the blade elements, and 2) that fluctuations averaged over the array are considerably reduced relative to the single hub-height record, because the wind is not perfectly correlated at each anemometer. While these results were not entirely unexpected, this experiment provides quantitative data that can be applied to turbine design.

The original installation has been replaced by a 49-m array, and the 24.4-m array has been moved to a position perpendicular to the plane of the large array. The upwind fetches of the two arrays have 
different characteristics. It is expected that possible effects of these differences may be identified. In addition, the data from the two different-sized arrays will be studied to identify possible scaling relationships. Several hours of data have already been collected on the large array. Winds have not been favorable for data acquisition on the smaller array.

The new data have been scanned to identify unusual windflow patterns, and analysis schemes have been reviewed ir. anticipation of full-scale analysis activities. These will be directed toward describing those features of the windfield, which are of particular interest to WECS designers and engineers, such as direction change statistics, coherence of gusts and gust exceedance statistics.

Expected Progress During Next Reporting Period:

PNL will continue its analysis of the original data set and will begin analysis of new data. The data will be examined for differences as a result of changes in array dimension.

Reports and Publications:

M. G. Verholek, Preliminary Results of a Field Experiment to Characterize Wind Flow Through a Vertical Plane. PNL-2518, Battelle, Pacific Northwest Laboratories, Richland, WA 99352, April 1978 .

W. C. Cliff and M. G. Verholek, "Flow Field Analysis." PNL-SA-2739. Proceedings of the 1977 Workshop on Wind Turbine Structural Dynamics Conference, NASA/Lewis, Cleveland, Ohio, November 15-17, 1977. 


\subsubsection{Flow Through a Vertical Plane: Supplementary Gauss- Markov Analysis (Ale)}

Pacific Northwest Laboratory

Richland, WA 99352

Principal Investigators:

T. C. Kerrigan

J. C. Doran (509) 942-4763

Objective:

To develop a statistical-prediction technique for atmospheric turbulence, using a Gauss-Markov model. The technique uses the history of wind fluctuations for a few seconds prior to a given time as a basis for computing probable wind values in the near future.

Program status:

This program, which began in FY-1978, is essentially finished, pending completion of two reports describing the mathematical basis of the technique and a third report summarizing the results obtained from an application of the method to data obtained from an array of anemometers.

Progress During Reporting Period:

The Gauss-Markov method was successfully developed and applied to data obtained from the 24.4-m array. The data were selected to be representative of a wind environment that a WECS might experience. Little or no improvement in prediction capability was found when compared with simple Markov, i.e., Dryden spectrum, approaches. Analysis of the results indicated that no characteristic structures of turbulence exist that might be useful for the prediction of future fluctuations. 
Expected Progress During Next Reporting Period:

Three reports, which describe the approach and summarize the results, will be completed.

Reports and Publications:

T. C. Kerrigan, Spectral Estimates of a Wind Fluctuation Statistic Pertaining to Wind Energy

Generators. PNL-2511, Battelle, Pacific Northwest Laboratories, Richland, WA 99352, september 1978.

T. C. Kerrigan, A Technique for Analyzing the

Structure of Atmospheric Turbulence. PNL-2509, Battelle, Pacific Northwest Laboratories, Richland, WA 99352, September 1978.

T. C. Kerrigan, A Verification Statistic for Numerical Wind Models. PNL-2510, Battelle, Pacific Northwest Laboratories, Richland, WA 99352, September 1978 . 
2.1.5 Meteorological Instrumentation and Data Analysis Reguirements for Performance Evaluation (Ā2)

Contract Number: 5189-76-32

Sandia Laboratories

Albuquerque, NM 87115

Principal Investigator:

Robert E. Akins (505)264-1087

Contract Monitor:

W. C. Cliff (509)946-2024

Objective:

To develop uniform field-test procedures, data collection and data-analysis techniques to be used on meteorological measurements for WECS performance evaluation.

Program Status:

A decision on whether or not to continue this effort will be made at the end of FY-1978.

Progress During Reporting Period:

The method used by Sandia to relate the wind speed measured to a wind turbine's power was documented. This method is called the method of bins and is applied by dividing the wind regime into a number of velocity increments, recording the times each of these increments is realized, and measuring the corresponding performance of the wECS during those intervals.

Expected Progress During Next Reporting Period:

A standard field-test set-up guide to be used for a wind turbine's performance evaluation will be completed; however, the expected progress depends upon whether this effort is continued. 
Reports and Publications:

Robert E. Aikins, Performance Evaluation of Wind Energy Conversion Systems Using the Method of Bins-Current Status. Sandia 77-1375, Sandia Laboratories, Albuquerque, NM 87115, March 1978. 
• 


\subsection{MESOSCALE WIND CHARACTERISTICS}

The wind resource on a national level is fairly well defined, as a result of the national assessments by Sandia, Lockheed, and General Electric and the synthesis of these national assessments by PNL. At the same time, the shortcomings of these assessments have also been well defined. The assessments do not provide the level of detail and refinement necessary for planning WECS installations. Several reasons exist for this limitation:

- insufficient analysis of an existing, detailed data base

- insufficient techniques for extrapolating existing measurements made at various heights and under different exposures to a standard height

- insufficient techniques for quantifying the resource in regions where no data exist

- insufficient methods for defining the frequency distributions of wind speed at each data location and the representativeness of these distributions within a region where no data exist

- insufficient knowledge of the regional crosscorrelations of wind characteristics for use in optimization studies for dispersed arrays of WECS.

Current research in the Mesoscale Wind Characteristics Program area is focused on these deficiencies.

This program area has two main objectives: to identify and quantify the total available wind resource over a large region, specifying locations of favorable wind-energy potential to which siting methodologies can be applied for specific machine installations, and to quantify the wind characteristics at a 
preselected site by using nearby long-term meteorological data. To achieve these goals, research tasks are focused toward improving our understanding of the wind resource over a large area and at a specific site even where existing long-term meteorological data are not readily available.

Prototype techniques have been developed to screen all available data over a large region and to incorporate these data into a large-area analysis. These techniques include procedures for eliminating unsummarized data from the National Climatic Center, which do not indicate sufficient wind for WECS implementation and for screening other sources of unsummarized data so that a thorough large-area analysis of wind-energy potential can be completed. Unique sources of data have been identified, and their usefulness in developing an analysis of wind-energy potential over a large area has been assessed (see Task Bla).

Areas showing particular promise for wind-energy use have been given special attention. The national assessments indicated portions of the United States' East and Gulf Coasts that have high wind-energy potential, even though the regional wind energy available is quite low according to existing data used in the studies (see Task B3h). Another area where wind-energy potential appears to be good is in mountainous terrain. However, wind data are usually scarce in these areas. Some research is underway to better define the wind resource in mountainous terrain and to optimize siting procedures in the area (see Task B $3 \mathrm{~g})$. Information from these tasks will provide valuable input into the large-area analyses in the context of assessing the national wind-energy potential and providing detailed information for planning WECS implementation.

At present, some basic techniques are available for extrapolating wind data to a given height so that all data used in a large-area analysis are representative of the same height. These techniques use a simple power-law relationship, usually 
1/7, which is determined from an analysis of historical weather data at the site (see Task B3d). Other techniques are available for extrapolating the Weibull parameters, so that the distribution around the mean can be projected to the desired height (see Task B3e). If the data are extrapolated prior to inclusion in interpolation techniques, the $1 / 7$ power law or power laws determined from various stability classes and surface roughness characteristics are used (see Tasks B2C, B3h, and $\mathrm{B} 3 \mathrm{i}$ ).

Despite the data screening and analysis procedures developed, many regions exist where data are insufficient or nonexistent. Several techniques are currently available, in various stages of completeness, to provide at least a qualitative indication of the wind resources in these regions. These techniques include:

- use of LANDSAT satellite imagery to locate areas of eolian landforms, which represent potentially high wind energy (see Task B3a)

- use of interview techniques to identify regions of high wind-energy potential where data are not available (see Task B3b)

- use of standard upper-air rawinsonde data to supplement regional wind-energy analyses (see Task B3b).

From these techniques, handbooks will be prepared, when necessary, to help planners study the feasibility of wind-energy use in specific regions.

In a large-area analysis, the distribution of the wind speed at a location is perhaps more important than knowledge of the mean wind speed, because wind speed distribution provides information on the efficiency at which different machines will perform. At present, the Rayleigh distribution appears 
adequate for purposes of preliminary assessment of machine performance when actual distribution data are not available, although the Weibull distribution provides a better fit to frequency distribution for high wind speed data (see Tasks B3e, $\mathrm{B} 3 \mathrm{~g}$, and $\mathrm{B} 3 \mathrm{i})$.

Statistical, numerical and onsite measurement programs are being studied to establish the most useful and accurate site evaluation procedures. Statistical studies indicate that using a ratio method to adjust short-term "candidate" site data to long-term nearby climatological data provides limited improvement in establishing long-term mean wind characteristics at the candidate site (see Task B3e). Improved confidence in climatological adjustment techniques can be obtained by factoring in the long-term mean annual correlation between the sites and the standard deviations about the means for the two sites (see Task B3c). However, this technique is also limited because the climatological cross-correlation and standard deviations must be estimated for the candidate site.

Numerical interpolation techniques can also be used to estimate wind characteristics at a candidate site when nearby long-term climatological data are available. Four studies have been completed, which developed and tested these techniques (see Task B2c). An evaluation of these techniques is currently underway (see Task B2d). Initially, the evaluation shows that al1 four methods provide better estimates in smooth terrain than in complex terrain and that no significant difference in the skill of the various techniques has been identified. 


\subsection{PROGRESS IN TECHNICAL TASKS}

3.1.1 Prototype Techniques for Analyzing the Wind-Energy Potential Over Large Areas (Bla)

Pacific Northwest Laboratory

Richland, WA 99352

Principal Investigator:

Dennis L. Elliott (509)942-4762

Objective:

To establish prototype techniques for analyzing the wind-energy potential over large areas and to test these techniques in describing the wind-energy potential for a selected area.

Program Status:

This project was initiated in November 1977 and will continue through early FY-1979. A final report on the prototype techniques is scheduled for completion in November 1978. The large-area analysis is to be completed in January 1979.

\section{Progress During Reporting Period:}

Prototype techniques have been developed for estimating and analyzing the wind-energy potential over large areas. These techniques involve methods for identifying, screening, and analyzing the available wind data for an area, and methods for using various indicators of the wind characteristics in areas where wind data are inadequate or nonexistent. The northwestern United states was selected as the area for testing the various techniques. All available data from the National Climatic Center, USDA Forest Service, and various other federal, state, and private organizations have been identified and screened for use in the northwestern wind-energy 
analysis. Figure 3-1 indicates the total number of data sources for each type of data listed and the relative contribution of each to the total number of stations. Figure 3-2 shows the distribution of fire weather stations, which have at least $70 \%$ of the observations above $3.6 \mathrm{~m} / \mathrm{sec}(8 \mathrm{mph})$.

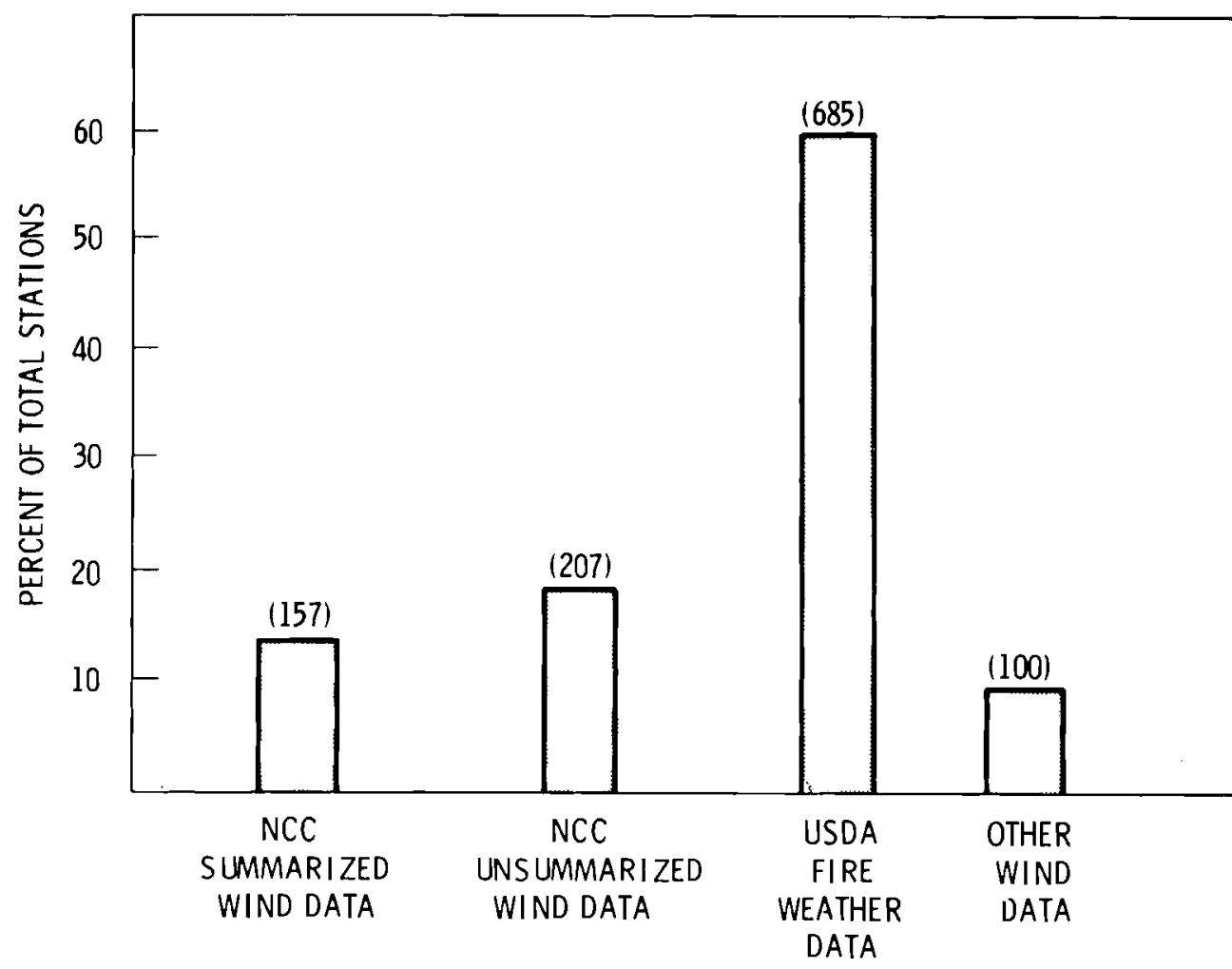

FIGURE 3.1. Types of Data Sources and Their Relative Contributions to the Total Number of Stations

Oregon State University, the University, of Wyoming, and Marlatt and Associates in Ft. Collins, colorado have been assisting PNL in applying and testing 
various techniques for the large area wind-energy analysis. The following draft reports have been received and reviewed:

- Oregon State University's "Vegetation as an Indicator of High wind Velocity: A Methodology for Determining Wind-Power Potential in the Pacific Northwest Coastal Region"

- University of Wyoming's "Eolian Features as Indicators of High-Wind Areas in the Pacific Northwest" and "Catalog of Available Wind Data in Idaho, Montana, and Wyoming"

- Marlatt and Associates' "Assessment of the Applicability of National Fire Weather Data to the Northwest Regional Wind-Energy Study."

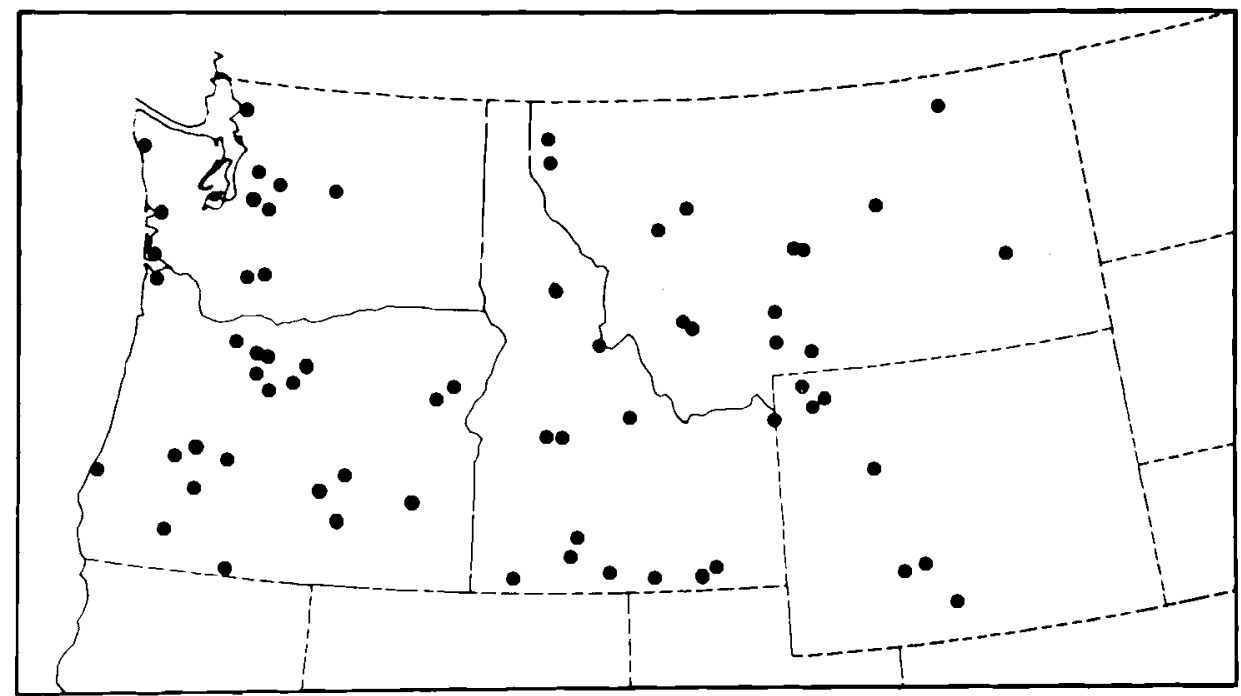

FIGURE 3-2. Fire weather Station with at Least $70 \%$ of Observations $\geq 8 \mathrm{mph}\left(3.6 \mathrm{~m} \mathrm{~s}^{-1}\right)$

PNL has investigated combinations of meteorological and topographical features, which are characteristic of high wind-energy areas. Also, the 
application of upper-air data from rawinsonde stations has been examined as a method for estimating the wind characteristics over exposed hills and mountains. In addition, a technique for estimating the percentage of land area over which various amounts of wind power are exceeded has been developed. This technique classifies land forms and the fraction of each classification favorable for the generation of wind power. Figure 3-3 shows the initial results of applying this technique to the wind-energy analysis of the state of Wyoming. An outline and a skeleton report of the prototype techniques for analyzing the wind-energy potential over large areas have been completed for review by DOE headquarters. In addition, a skeleton report of the large-area wind-energy analysis for the Northwest has been completed.

A working-group meeting is planned in september 1978 to discuss these prototype techniques and to plan additional large-area analyses.

Expected Progress During Next Reporting Period: The results of the information reported by oregon State University, University of Wyoming, and Marlatt and Associates will be synthesized and included in the PNL draft final reports on the prototype techniques and wind-energy analysis for the Northwest. Computer programs and various graphical displays that illustrate results and analyses will be completed. An atlas, including seasonal and annual wind-energy maps for each state in the Northwest study, will be prepared. 


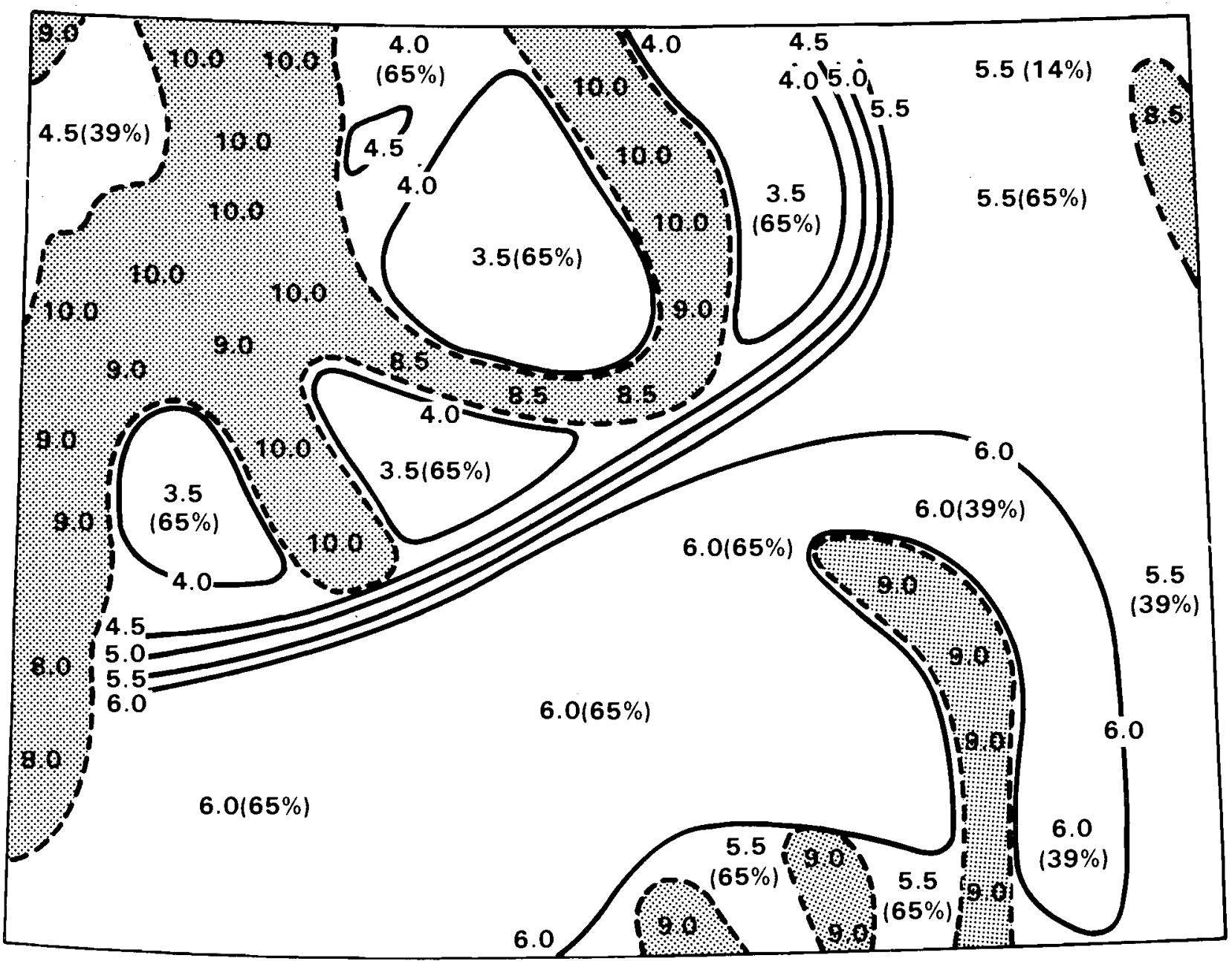

FIGURE 3.3. Mean Annual wind speed in $\mathrm{m} \mathrm{s}^{-1}$ at $10 \mathrm{~m}$. Numbers in () give percent of total land area over which the wind speed equals or exceeds the indicated value. In mountainous regions (shaded area), this is assumed to be $2 \%$. 
Reports and Publications:

D. L. Elliott. "An Overview of the National wind Energy Potential." PNL-SA-6569. Presented at the Conference on Climate and Energy: Climatological Aspects and Industrial Operations, Asheville, NC, May 8-12, 1978.

D. S. Renne and D. L. Elliott, "Overview of Techniques for Analyzing the wind Energy Potential Over Large Areas." PNL-SA-7062. Presented at the Solar 78 Northwest Conference, Portland, OR, July 14-16, 1978 . 


\subsubsection{MOD-OA and MOD-1 Candidate Site Meteorological Documentation (B2a)}

Pacific Northwest Laboratory

Richland, WA 99352

Principal Investigator:

David S. Renne (509) 942-4623

Objective:

To provide assistance to $\mathrm{DOE}$ in selecting sites for testing of large wind machines by analyzing and summarizing meteorological data from 17 candidate sites.

Program Status:

The program began in April 1976 and is continuing. Four installation sites have been selected: three for the MOD-OA (Block Island, RI, Clayton, NM, and Culebra Island, $P R$ ) and one for the MOD-1 (Boone, NC) .

\section{Progress During Reporting Period:}

Computer graphics have been developed to display on a single page the wind speed, frequency distribution characteristics of all 17 candidate sites. The actual distributions can then be compared with the Rayleigh distribution on these graphs. In addition, graphical displays of the power duration characteristics of specified machines can also be displayed on a single page for all 17 sites. An example of the frequency distribution of wind speed for 17 mo of onsite data collected at the 45.7-m (150 ft) level is shown in Figure 3-4. 

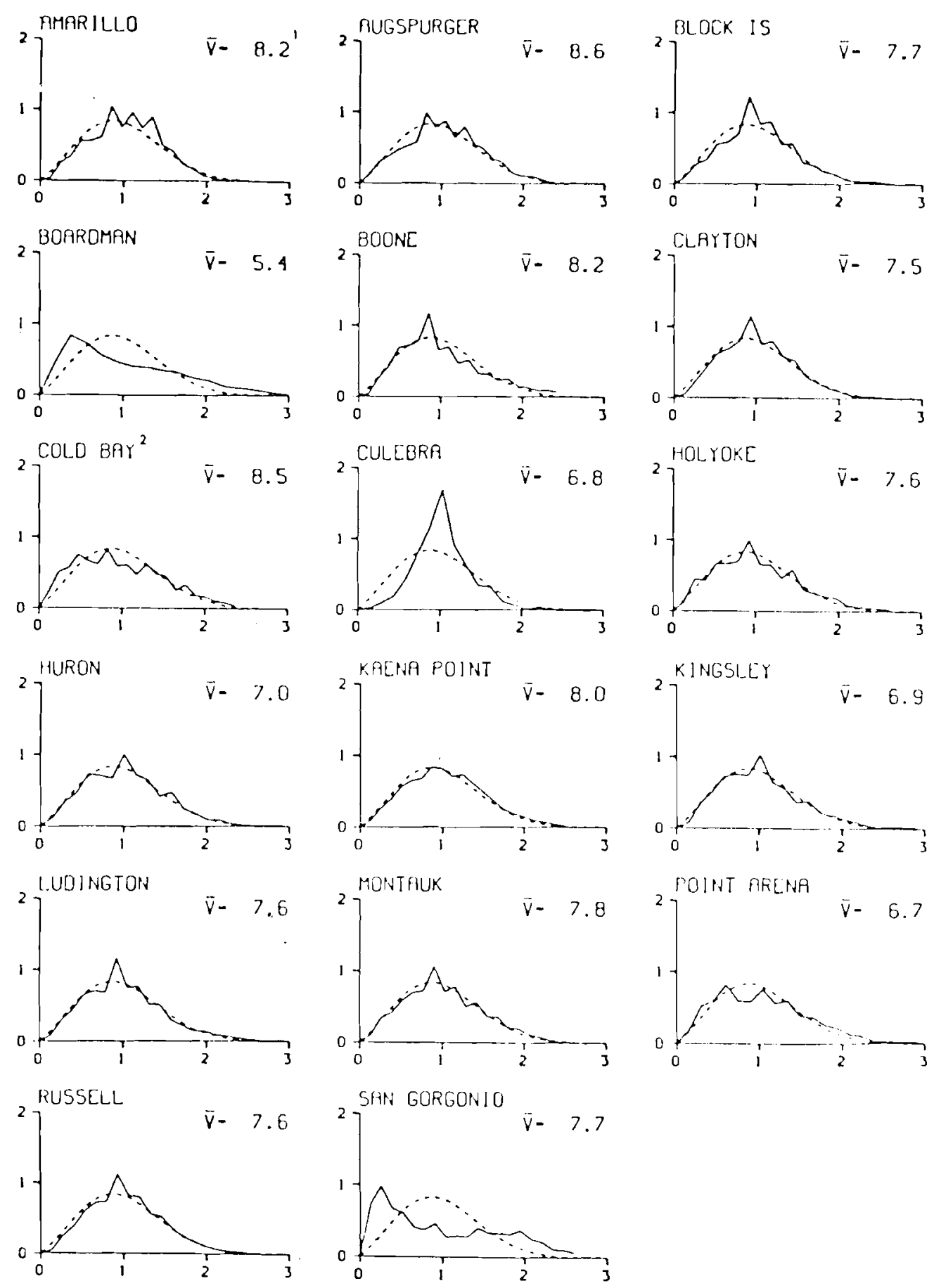

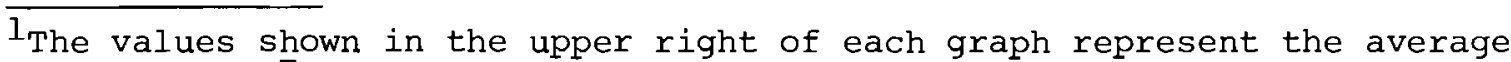
wind speed $(\bar{V})$. The solid curves represent the normalized frequency distributions from the 17 sites. The broken curves represent the NASA Lewis design distribution.

2 The curve shown here is based on data from the $21.8 \mathrm{~m} \mathrm{level.} \mathrm{There} \mathrm{are}$ no measurements made at $45.7 \mathrm{~m}$.

FIGURE 3-4. Normalized Wind Frequency Distributions (solid curves) at the $45.7 \mathrm{~m}$ Level $[(\overline{\mathrm{V}} \cdot \mathrm{p}(\mathrm{V})$ vs. $\mathrm{V} / \overline{\mathrm{V}}$, where $\mathrm{p}(\mathrm{V})$ is probability density.] 
Expected Progress During Next Reporting Period:

Analyzing and reporting summarized data collected at the original 17 candidate sites will continue. In October new instruments will be installed at the sites, and more refined data collection and analysis procedures will be implemented.

Reports and Publications:

None. 
3.1.3 Identification and Meteorological Documentation of Potential Sites for Testing Large Turbines and Wind Turbine "Farms" (B2b)

Pacific Northwest Laboratory

Richland, WA 99352

Principal Investigator:

David S. Renne (509) 942-4623

Objective:

To provide assistance to DOE for selecting candidate sites and installation sites for testing large turbines and wind turbine demonstration "farms."

Program Status:

The planning stage of this program was initiated in october 1977. The program will continue for several years as new candidate sites are selected and as installation sites are chosen for operational testing of large turbines and wind turbine "farms."

Progress During Reporting Period:

A draft Program opportunity Notice (PON) has been prepared. The PON is going through final DOE review.

Expected Progress During Next Reporting Period: The PON should be released sometime in FY-1979. From the utility responses to the PON, additional candidate sites will be selected. Meteorological equipment will be installed on these sites, which do not have adequate measurements, and a data retrieval and analysis program will begin. The equipment will be identical to that planned for 
installation at the original 17 candidate sites (see Task B2a).

Reports and Publications:

None. 
3.1.4 Techniques for Estimating wind Characteristics at Potential wind Energy Conversion Sites (B2C)

Contract No.: B-29083-A-E

Geomet, Incorporated

15 Firstfield Road

Gaithersburg, MD 20760

Contract No.: B-29105-A-E

SRI International

333 Ravenswood Avenue

Menlo Park, CA 94025

Contract No.: B-29084-A-E

Center for the Environment and Man, Inc.

275 Windsor Street

Hartford, CT 06120

Contract No.: $\quad$ B-29082-A-E

Meteorology Research, Incorporated

Box 637

Altadena, CA 91001

Principal Investigators:

Robert C. Koch (Geomet) (301)948-0755

Chandrakant M. Bhumralkar (SRI) (415) 326-6200

Marshall A. Atwater (CEM) (203)549-4400

Steven M. Howard (MRI) (213)791-1901

Contract Monitor:

David S. Renne (509) 942-4623

Objective:

To provide a description of a technique for estimating wind characteristics at a site on the basis of available data at other locations and to provide estimates of pertinent hub-height wind characteristics at eight specified locations.

Program Status:

These four contracts began in the summer of 1977 and were completed by July 1978 . 


\section{Progress During Reporting Period:}

In this task, techniques were developed for interpolating wind characteristics. The evaluation of these techniques is discussed in Task B2d.

Geomet: Long-term meteorological data from nearby National Weather Service stations were obtained for eight potential wind energy conversion sites (Boardman, OR; San Gorgonio Pass, CA; Huron, SD; Russell, KS; Ludington, MI; Boone, NC; Holyoke, MA; and Montauk Point, NY). Geomet's method extrapolated these long-term data to a specified hub height, using a power-law relationship. Several observations were averaged, using an inverse, distance-squared, weighting factor to get a site estimate. The site estimate was then adjusted for local topographical effects. Long histories of hourly observations (15 to $20 \mathrm{yr}$ ) were used to generate statistical characteristics of the estimated site winds, including mean wind speed, frequency distributions of wind speed (including seasonal and diurnal variations), wind roses and run durations of selected classes of wind speeds.

SRI: This method for estimating wind characteristics uses a mass-consistent windflow model to interpolate between stations where wind data are available. Input data, obtained from nearby National weather Service stations around the eight sites, are resolved into orthogonal components along the set of eigenvectors of the covariance matrix. The solution for each eigenvector is determined with the model; the hourly interpolated winds are then formed from linear combinations of 
these solutions. The procedure requires:

1 ) acquisition and merger of wind data from three to five stations, 2) application of the model to each of the 7 to 11 (depending on the number of stations for which wind data are available) eigenvectors, 3) reconstruction of the hourly interpolate winds at the site from the eigenvector solutions, and 4) estimates of the wind characteristics from the simulated hourly values.

CEM: Recent data from nearby (within $200 \mathrm{~km}$ ) National weather Service Stations were acquired. wind statistics were generated by a program, which used various wind-profile equations, surfaceroughness characteristics, atmospheric stability and other elements to produce the required wind statistics at any elevation. A horizontal interpolation program was then used to translate the statistics generated at more than one observing station into estimates of statistics at the potential WECS site. Weights, based on the data consistency, topographical effects, and effects of nearby water bodies, were assigned to the various station statistics for the purpose of obtaining more representative statistics for the WECS site under consideration. Interpolation was carried out on the statistics, not the hourly, values.

MRI: The technique utilizes a numerical airflow model to establish a relationship between the winds at the candidate site and the winds occurring at a nearby observing station. Station winds and the regional terrain configuration are put into the model. The model computes the windfield at the 
site from any given set of input winds at the stations by calculating a flowfield adjusted to the terrain. The resulting site winds are mathematically related to the input station winds by computing "modeling functions" for each station's wind direction. These modeling functions are then applied to 15 yr of hourly station wind observations to generate site wind-character summaries. The methodology of constructing a site windcharacter climatology, then, involves the application of the airflow model to compute site winds and the construction of the modeling function expressions from the model results.

Expected Progress During Next Reporting Period:

This contract is closed.

Reports and Publications:

Robert C. Koch and Kenneth E. Pickering, A Method for Estimating wind Characteristics at Potential Wind Energy Conversion Sites. Geomet, Inc., 15 Firstfield Road, Gaitherburg, MD 20760, July 1978.

C. M. Bhumralkar, F. L. Ludwig, and R. L. Mancuso, Estimation of wind Characteristics at Potential Wind Energy Conversion Sites. SRI International, 333 Ravenswood Avenue, Menlo Park, CA 94025, April 1978.

Robert J. Ball, Marshall A. Atwater, and John T. Ball, Estimates of Wind Characteristics at Potential Wind Energy Conversion (WECS) Sites. The Center for the Environment and Man, Inc., 275 Windsor Street, Hartford, CT 06120, January 1978. 
S. M. Howard and P. C. Chen, Estimation of Wind Characteristics at Potential Wind Energy Conversion Sites. Meteorology Research, Inc., 464 West Woodbury Road, Altadena, CA 91001, March 1978. 


\subsubsection{Evaluation and Implementation of Wind Prediction Techniques at Potential Sites (B2d) \\ Pacific Northwest Laboratory \\ Richland, WA 99352 \\ Principal Investigator:}

David S. Renne (509) 942-4623

Objective:

To evaluate the interpolation procedures developed in Task B2C to determine the usefulness and applicability of one or more techniques at predetermined sites in various topographic/climatic regimes and to implement one or more of the techniques, or a hybrid technique, as part of the evaluation procedures for selection of sites for machine installation.

Program Status:

This effort was started in March 1978 as the contract efforts in Task B2c neared completion and will be completed in March 1979.

Progress During Reporting Period:

The wind characteristics for eight candidate sites used by the contractors in Task B2C were compared with actual onsite measurements obtained from DOE/ NASA wind-measuring equipment. Evaluation of the efficiency, cost-effectiveness, and ease of applicability of each technique was begun. Table 3-1 shows the mean annual wind speed calculated by each technique as compared to the actual wind speed measured at the site over 1 yr. A preliminary statistical analysis of these results is underway; each of the four techniques works equally well. Initially, the techniques are more successful over smooth than over complex terrain. 
Expected Progress During Next Reporting Period:

Each technique will be ranked according to various criteria, including the validity, accuracy and efficiency of the methodology, and their capability to reproduce observed statistics for various terrain categories. Technical documents and user's manuals will be prepared on the techniques most applicable for different types of terrain/ climatic regimes.

Reports and Publications: None. 
TABLE 3-1. Comparison of Measured vs. Estimated Site Mean Annual Wind Speeds at $45.7 \mathrm{~m}, \mathrm{~m} / \mathrm{s}$

\begin{tabular}{|c|c|c|c|c|c|}
\hline Site & Data $^{l}$ & $\mathrm{MRI}^{2}$ & $\mathrm{SRI}^{3}$ & $\mathrm{CEM}^{4}$ & GEOMET $^{5}$ \\
\hline Boardman & 6.9 & 5.4 & 5.1 & 4.4 & 3.8 \\
\hline Boone & 8.0 & 3.7 & 9.7 & 7.1 & 3.5 \\
\hline Holyoke & 7.4 & 7.7 & 6.3 & 7.6 & 5.3 \\
\hline Huron & 7.0 & 8.2 & 9.5 & 6.2 & 7.2 \\
\hline Ludington & 7.5 & 5.6 & 7.6 & 7.0 & 5.5 \\
\hline Montauk & 7.5 & 6.1 & 8.2 & 6.3 & 5.5 \\
\hline Russell & 7.6 & 9.1 & 9.5 & 7.3 & 7.8 \\
\hline San Gorgonio & 7.6 & 2.9 & 3.3 & 4.7 & 4.2 \\
\hline
\end{tabular}

1 Based on 1-yr onsite data obtained from DOE/NASA met. towers

$\begin{array}{ll}2 & 15-y r \text { data base } \\ 3 & 1-y r \text { data base } \\ 4 & 5-10-y r \text { data base } \\ 5 & 15-20-y r \text { data base }\end{array}$ 
3.1.6 Locating High Wind Areas by Remote Observations of Eolian Features (B3a)

Contract No.: EY-76-S-06-2343

University of Wyoming

Department of Geology

Laramie, WY 82071

Principal Investigator:

Ronald W. Marrs (308)766-2330

Contract Monitor:

David S. Renne (509)942-4623

Objective:

To develop an efficient way to identify high windenergy sites by inferring wind characteristics from eolian geomorphologic features mapped from LANDSAT and aircraft imagery and to determine the geographic applicability of these techniques.

Program Status:

This program was initiated in september 1976 and the current phase of work will continue through September 1978.

Progress During Reporting Period:

Three tasks were identified in the renewal of contract EY-76-S-06-2343 (Modification A004):

- to develop interpretation techniques for determining wind characteristics from eolian features,

- to assess the regional applicability of interpretation of satellite imagery,

- to demonstrate the techniques in a regional evaluation of eolian features in the Pacific Northwest. 
Work included under Task I comprised the basic research items, which laid the groundwork for later applications. Emphasis was placed upon these work items through 1977. Several useful indicators of wind characteristics were identified and techniques were developed for semiquantitative estimates of wind velocity. The 1978 contract period emphasized application of the new techniques to selected test areas to demonstrate the potential of the new tools and to identify additional basic research requirements. Progress under each of the major research tasks is summarized below.

Task I: Interpretation Technique. This task includes continued analysis of available data to improve the capability to interpret wind characteristics from dunes and playa lakes and an effort to present the useful techniques as a tool to user communities. Critical work items include:

- Evaluate thoroughly the Inman procedure or other "rate of movement" relationships for estimating wind velocities.

- Compare grain-size data from the Seminoe area with local wind-velocity data, and evaluate "grain-size" as a mean velocity indicator.

- Complete analysis of low-altitude aircraft data for comparison with image interpretations and sedimentological data and proceed as far as possible to characterize the flow pattern.

- Continue efforts to define actual mechanisms for gravity-wave flow. 
- Compile a handbook describing the use of eolian features as indicators of wind characteristics.

Estimates of mean wind velocity computed from "migration rate" and the "grain-size" equations have produced reasonable values for the Seminoe test region. However, in-depth evaluations of these empirical equations indicate both theoretical and practical inconsistencies in the equations. Currently the equations are being reworked to eliminate (or explain) these inconsistencies. Summarized aircraft data have been incorporated into evaluations of the interpretations of eolian features and the theoretical work with atmospheric gravity waves.

Preparation of a handbook, which will describe the procedures for interpreting wind characteristics from eolian features has begun. This handbook will allow users who lack experience in geomorphology and photo-interpretation to identify many of the eolian features useful as indicators of wind characteristics.

Task II: Assessment of regional applicability interpretations of eolian landforms was completed for southern Wyoming, for southeast Washington, and for the southern Great Plains. In addition, a map has been compiled showing the major areas of the continental United States susceptible to eolian activity.

Task III: Assessment of the Pacific Northwest region preliminary interpretation was made from 1:500,000-scale LANDSAT image mosaics and from $1: 1,000,000-s c a l e$ LANDSAT imagery of the Pacific 
Northwest. Concentrations of eolian features were identified and mapped as indicators of high wind areas in the Pacific Northwest region (see Figure 3-5). The distribution of eolian landforms in the Pacific Northwest shows that eolian landforms are common and should be extremely useful for broad-scale and local wind-energy assessments in that region.

Sources of wind data, other than the national weather service, have been identified and cataloged for Idaho, Montana and Wyoming. In this region $\sim 100$ surface wind sites and $\sim 12$ instrumented towers have been located, which record data of significant value to a wind energy assessment.

Expected Progress During Next Reporting Period:

A summary report on the work in the Seminoe test area has been compiled and figures are now being drafted for that report. The equations for calculating mean wind velocity from grain size and dune migration rate are being evaluated. The handbook describing the interpretation procedure and the catalog of wind data in the Wyoming, Montana, Idaho portion of the Pacific Northwest region is being completed. An example handbook will be prepared demonstrating the use of eolian features in small-, intermediate-, and large-scale assessment of windenergy potential by image interpretation. Turbulent kinetic energy budqets, vertical momentum fluxes and sensible heat fluxes are being calculated from the aircraft data gathered over various topographic and eolian features. 


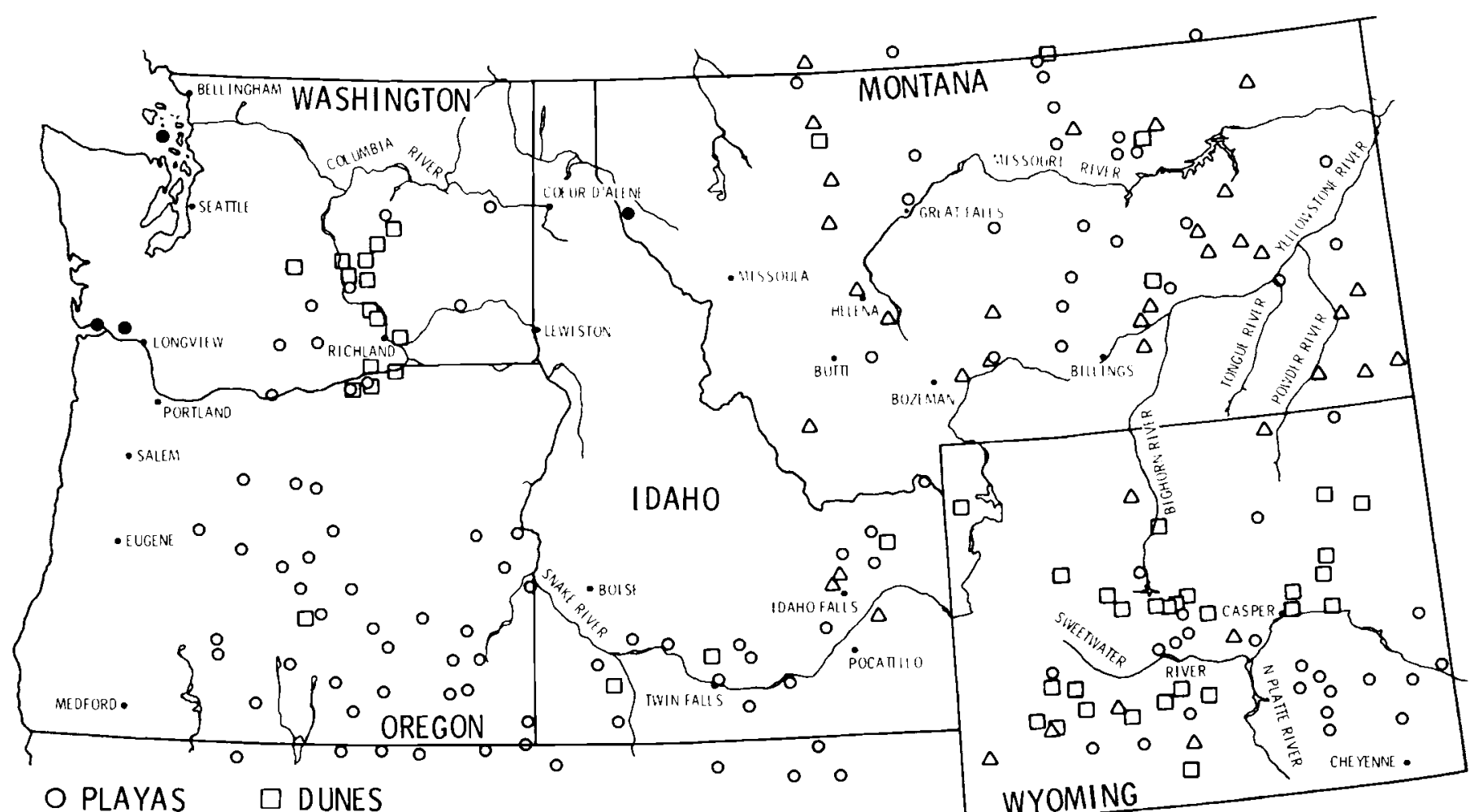

$\triangle$ SCOUR - AEROSOLS

FIGURE 3-5. Map of Eolian Landforms in the Pacific Northwest 


\author{
Reports and Publications: \\ R. W. Marrs and S. Kopriva, Regions of the \\ Continental United States Susceptible to Eolian \\ Action. Special Report, RLO/2343-78/2, University \\ of Wyoming, Laramie, WY 82071, 1978. \\ R. W. Marrs and J. Marwitz, "Locating Areas of \\ High Wind-Energy Potential by Remote Observation \\ of Eolian Geomorphology and Topography." Proceed- \\ ings of the Third Wind Energy Workshop, Washington, \\ D.C., September 19-21, 1977.
}


3.1.7 Innovative Techniques for Locating and Evaluating High-Wind Areas (B3b)

Contract No.: B-29083-A-E

North American Weather Consultants

600 Norman Firestone Road

Goleta, CA 93017

Principal Investigator:

Max W. Edelstein (805)967-1246

Contract Monitor:

David S. Renne (509)942-4623

Objective:

To obtain quantitative estimates of the long-term mean wind speeds at a height appropriate to wind energy conversion systems in data-sparse regions.

Program Status:

This contract began in February 1978 and will be completed in October 1978.

Progress During Reporting Period:

Two nuclear power plants were selected as sites for this research project: one with moderate terrain (Pebble springs, $O R$ ) and the other witr rugged terrain (Phipps Bend, TN). Data collected for both of these sites included: heights and temperatures at $850 \mathrm{mb}$; winds from two levels of meteorological towers; and maximum-minimum temperatures and cloud cover from nearby stations.

The initial work was divided into five areas:

- The 850-mb data were obtained from microfilm at the National Climatic Center.

- USGS large-scale charts were obtained for each site and a computer program was developed to 
determine surface roughness and displacement height using terrain data.

- An independent procedure was developed for determining surface roughness and displacement height using the log-linear velocity relationship with wind data from two different heights of the meteorological tower.

- Necessary computer programs were prepared.

- A literature review to determine a relation for the power index as a function of surface roughness and stability continued.

Expected Progress During Next Reporting Period:

The analyses for the two sites will be completed, and a final report summarizing the techniques and the results of the analysis will be submitted. Testing of the method will involve:

- generating three-hourly 850-mb winds,

- correlating surface winds to the 850-mb winds for a period of three months,

- computing long-term surface-wind distributions from long-term 850-mb wind observations,

- comparing computed and actual surface wind distributions,

- testing the sensitivity of the method by varying the input parameters over the range of expected maximum error.

Reports and Publications:

None. 

3.1.7a Innovative Techniques for Locating and Evaluating

Contract No.: $B-36379-A-E$

The University of Texas

Atmospheric Science Group

Austin, $\mathrm{TX} 78712$

Principal Investigator:

Norman K. Wagner (512)471-3611

Contract Monitor:

David S. Renne (509) 942-4623

Objective:

To develop a technique for determining the space and time variations of wind speed in data-sparse coastal areas by interviewing appropriate local residents.

Program Status:

This study began in February 1978 and will continue through February 1979.

Progress During the Reporting Period:

Accomplishments during the first four and one-half months of this contract include:

- Oral interview procedures for offshore, inshore and bay areas have been prepared.

- Suitable interviewees have been located by contacting the Corpus Christi Yacht Club and a charter fishing boat captain organization in Port Aransas, Texas.

- A historical wind-data base, available from the National Weather Service, the Naval Air Station in Corpus Christi and the Coast Guard in Port Aransas has been identified. Additional 
meteorological information at Port Aransas, TX, include data from a $30-\mathrm{m}$ research tower about $0.5 \mathrm{~km}$ inland at the Marine Science Laboratory of the UniversitTexas and data from a wind instrument mounted about $10 \mathrm{~m}$ above the water on Caldwell Pier.

Expected Progress During Next Reporting Period:

A number of interviews will be conducted with individuals who frequent one or more of the coastal regions, i.e., the bays, inshore waters, or offshore regions of the Gulf of Mexico. The results of these interviews will be summarized and correlated with the available wind data. Additional over-water, wind-measuring sites are planned: one on an oil or gas platform in the Gulf of Mexico and another in Corpus Christi Bay.

Reports and Publications:

Steven L. Eigsti, The Coastal Diurnal Wind Cycle at Port Aransas, Texas. Atmospheric Science Group, Report No. 48, The University of Texas at Austin, Austin, TX, July 1978. 
3.1.8 Survey Methodology and Reliability Analysis for Site Wind Characteristics (B3C)

Contract No.: EY-76-S-06-2342

Northwestern University

Evanston, IL 60201

Principal Investigator:

Ross B. Corotis (312) 492-3453

Contract Monitor:

David S. Renne (509)942-4623

Objective:

To develop and apply complete procedures for site wind evaluation, using probabilistic and statistical methods and models. The reliability of the characteristics is to be established.

Program Status:

This contract began in October 1976 and was completed in september 1977. The contract was renewed in September 1977 and will be completed in October 1978 .

Progress During Reporting Period:

A complete candidate-site, data-enhancement procedure, which includes estimating the long-term climatic mean wind speed within specified confidence intervals, was developed for one or two longterm reference sites. The procedure indicated, using data and an alternative theoretical model, that 1 yr of hourly data is sufficient to predict long-term, seasonal, mean wind speed to within $10 \%$ of the true mean at a confidence level of $90 \%$. A simplified power-exponential, run-duration model was derived from statistical theory. The model 
uses a single calibration curve, which is a function of site mean wind speed. A correction procedure was developed for 3 -hr data.

The Chi-2 model was verified as a reliable predictor for wind speed distribution, and an assessment was made that the error is generally less than the inherent year-to-year variability for different speed levels.

Annual wind speed cycles were found to be consistent for various sites in a region; therefore, one season of data can be used to predict the longterm, seasonal, mean wind speed for a different season at that site within $10 \%$ of mean monthly wind speeds with a confidence level of $60 \%$. This prediction requires use of a regional annual cycle. A preliminary, simplified technique was developed for the simulation of the time series of power output from a spatial array of wind turbines.

Expected Progress During Next Reporting Period:

A study will be made of spatial correlations from hourly, daily, monthly, seasonal, and annual average wind speeds to determine general trends in correlation as a function of averaging times. This will include an assessment of sensitivity to anemometer height changes.

A test of the reliability of the power-exponential, run-duration model will be made to compare lack of fit with inherent year-to-year variability.

Data from three Pacific Northwest sites with irregular terrain will be analyzed to assess the capability of the models. 
Specific National Climatic Center sites will also be analyzed to check the models and to compare the data to that of nearby U. S. Forest Service fire weather stations, which make one wind observation per day during the summer and fall fire weather season. Selected data from the U. S. Forest Service will be studied to develop a technique for mapping winds over given regions and to assess confidence levels that can be established from single daily readings.

A record of averaged 20 -sec readings will be analyzed to determine the effect of averaging time and sampling interval on the Chi-2 and run-duration models.

Reports and Publications:

R. B. Corotis, A. B. Sigl, and J. Klein,

"Probability Models of Wind Velocity Magnitude and Persistence." Journal of Solar Energy, Vol. 20, No. 6, 1978, pp. 483-494.

R. B. Corotis, "A Probabilistic Basis for Wind Power Siting." Proceedings of Third U.S. National Conference on Wind Engineering Research, Ft. Lauderdale, FL, p. II-18-1, 1978.

R. B. Corotis, "Stochastic Consideratjons in site Survey Design." Proceedings of the Third Wind Energy Workshop, Washington, D.C., September 19-21, 1977. 


\subsubsection{Meteorological studies for Wind Power (B3d)}

Contract No.: $5189-76-32$

Sandia Laboratories

Albuquerque, NM 87185

Principal Investigator:

Jack W. Reed (505) 264-3042

Contract Monitor:

David S. Renne (509)942-4623

Objective:

To develop data-processing techniques that use standard National Weather Service archived observations for defining various aspects of wind-power availability, including time-dependent statistics, wind-turbine, speed-limit effects and run-duration statistics.

Program Status:

This program was started in 1973. Computer programs and data processing are essentially completed, and final reports are in preparation.

\section{Progress During Reporting Period:}

A report in preparation describes data-processing techniques and applications of various methodologies to records from 15 selected National Weather Service Stations around the United States. The first step in applying these methodologies was to adjust the collected speed distributions to changing anemometer exposures. From these data, wind-speed distributions have been developed for four standard heights (final anemometer height, $10 \mathrm{~m}, 20 \mathrm{~m}$, and $50 \mathrm{~m}$ ) at each of the selected stations (see Figure 3-6). 
Time-dependent statistics of wind-power availability have been calculated for months, seasons, years, and ten-year periods. Assumptions about turbine speed limits (cut-in, rated, cutoff speeds) have been used to show the effect of wind climate on total available power collected by specific turbines. Run-duration statistics have been calculated from some of the data.

A supplement to "Wind Power Climatology of the United States" is being prepared. It will include monthly average wind speeds and corrections to available wind power for local pressure altitude and nonstandard anemometer exposure. Estimates of power at $10 \mathrm{~m}, 20 \mathrm{~m}$, and $50 \mathrm{~m}$ will be included.

Expected Progress During Next Reporting Period:

A supplement to "Wind Power Climatology of the United states" and a report on climate effects on turbine speed-limit assumptions will be submitted for review. A tabulation of the number of turbine starts, depending on site climate and turbine height and cut-in speed, will be completed. Further calculations of the interannual variability of wind power will be made.

Reports and Publications:

J. W. Reed, "Availability of Wind Power." Proceedings of Electrobras/SUDENE Seminar on Wind Energy for Electrical Generation, Recife, Brazil, February 13-16, 1978. 


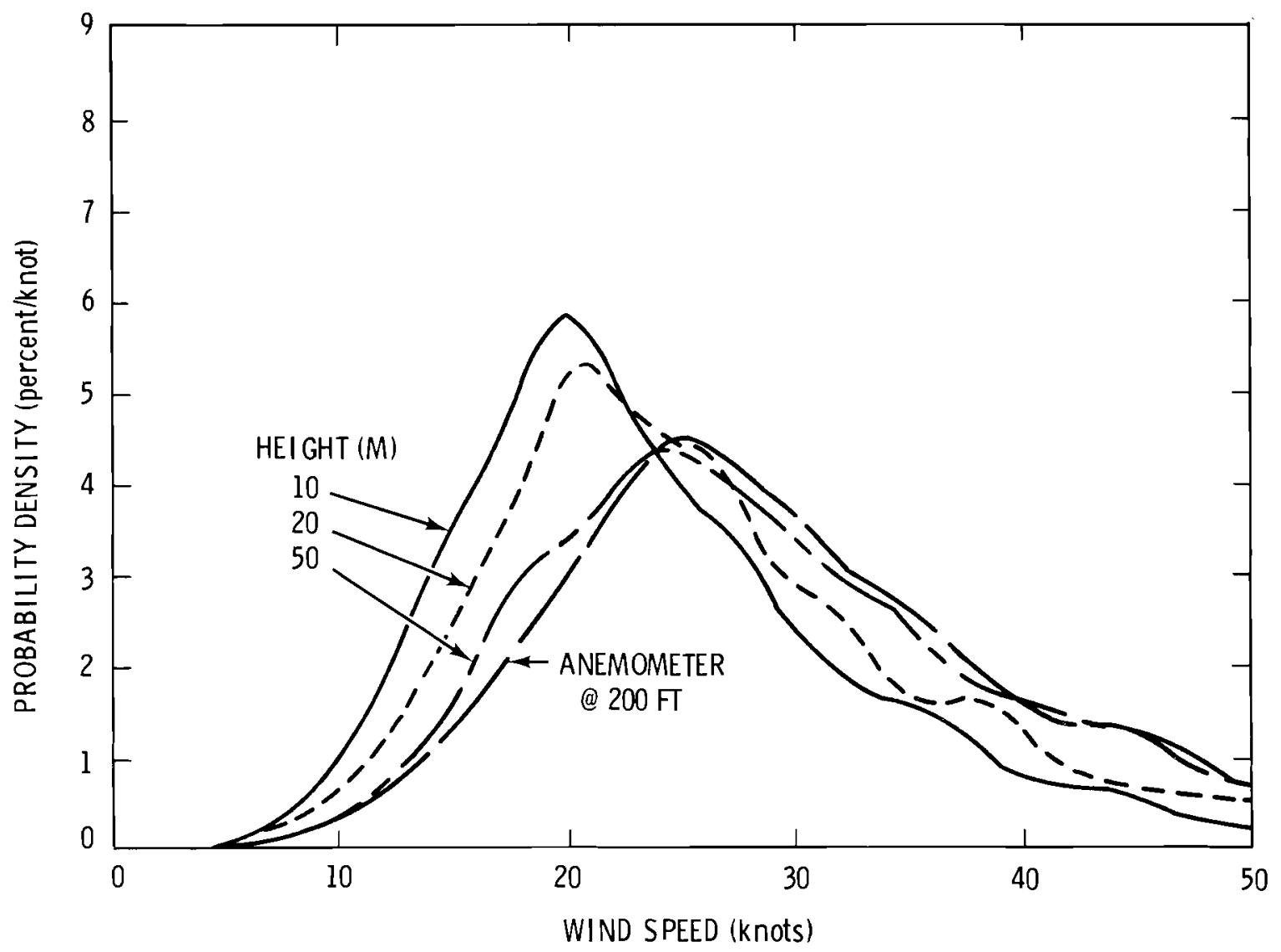

FIGURE 3-6. Wind Speed Distribution at Four Anemometer Heights 


\subsubsection{Energy Statistics for Large Wind Turbine Arrays (B3e)}

Contract No.: EY-76-S-06-2439

Georgia Institute of Technology

Atlanta, Georgia 30332

Principal Investigator:

C. G. Justus (404)894-3014

Contract Monitor:

D. S. Renne (509) 942-4623

Objectives:

To develop, test and apply the methods for estimating the effects of wind characteristics on various aspects of the performance of a WECS in large arrays and as an individual unit.

Program Status:

This program has been renewed and will continue through May 1979.

Progress During Reporting Period:

A generic array model has been developed, which allows array wind power statistics to be simulated from single representative site input. The required input parameters are: 1) average wind speed with appropriate seasonal and time of day variations, 2) maximum separation distance between sites in the array, 3) number of sites in the array, and 4) standard deviation of wind speed at the representative site. Sensitivity analysis with the model shows that an important factor in selecting the representative site input is average annual wind speed. Sensitivity of the array model to the other input parameters is only about half as great (or less) as the sensitivity to mean annual wind speed. 
This generic model has been adapted for use in two other research efforts. JBF Scientific Corp. (JBF, Final Report on EY-76-C-01-2438) and Ed Kahn of Lawrence Berkeley Labs (Kahn, LBL-6889) have used the methodologies developed in this project to evaluate WECS capacity credit, loss-of-load probability, and WECS penetration analysis. The array analysis techniques developed under this project were also expanded upon and prepared as a special PNL report (Cliff, Justus, Elderkin, PNL-2523).

A special study of interannual variations of wind speed has shown the following:

- Based on average interannual deviations $\sigma / \bar{V}$, a single observed annual mean speed will be within $\pm 10 \%$ of true climatological mean (with $90 \%$ confidence level). This confirms a similar estimate by corotis.

- About $10 \%$ of all sites would have annual $\sigma / \bar{V}$ values large enough that the $90 \%$ confidence level on one annual mean speed observation would be $\pm 15 \%$ relative to true climatological mean.

- Because of low spatial cross-correlations of monthly and annual mean winds, a simple proportional adjustment technique between "climatological" site and "candidate" site showed only marginal success in improving a single year of onsite data.

- Year-to-year variatations are sufficiently random that a lower-than-average wind speed year is only $60 \%$ likely to be followed by anotherlower-than average year, i.e., only slightly 
more likely than the 50\% expected for uncorrelated year-to-year variations.

Expected Progress During Next Reporting Period:

The array wind studies and generic models developed will be summarized and documented in a useroriented manual. Sensitivity of power-performance estimation to height-projection method (speeddependent power loss versus Monin-obukov theory) will be examined. Analytical and experimental studies will continue on the effects of speed and directional gusts and wind shear on power performance. Computer models developed will be compared against observed power performance on the Grumman Windstream 25 as a test case. Analytical and experimental studies will be initiated on windturning characteristics. Data analysis and windturning models to be developed will be compared against experimental results using the Grumman Windstream 25 as a test case.

Reports and Publications:

C. G. Justus, Winds and Wind System Performance. Franklin Institute Press, Philadelphia, PA, 1978.

C. G. Justus, W. R. Hargraves, A. S. Mikhail, and Denise Graber, "Methods for Estimating Wind speed Frequency Distributions." J. Appl. Meteorol., 17, $350-352,1978$.

C. G. Justus, "Wind Energy Statistics for Large Arrays of Wind Turbines (New England and Central U.S. Regions)." Solar Energy, 20, 379-386, 1978. W. C. Cliff, C. G. Justus, and C. E. Elderkin, Simulation of the Hourly wind speeds for Randomly 
Dispersed Sites. PNL-2523, Battelle, Pacific Northwest Laboratories, Richland, WA 99352, May 1978 . 


\subsubsection{Mesoscale Wind Characteristics in Mountainous}

Terrain (B3g)

Pacific Northwest Laboratory

Richland, WA 99352

Principal Investigator:

Montie M. Orgill (509)942-4628

Objective:

To identify, through an extensive literature review, current knowledge of wind characteristics in various types of complex terrain and to document the type of additional information that needs to be acquired for estimating wind characteristics and identifying high wind regimes over large areas of complex terrain.

\section{Program Status:}

This study began in July 1977 and will be completed in october 1978 after a draft final report that was submitted in December 1977 is revised.

Progress During Reporting Period:

An extensive review of the literature was undertaken. This review screened journal articles and reports describing results of field measurements, wind-tunnel studies, and theoretical studies of windflow in complex terrain. Based on this review, a draft report was written discussing current knowledge of windflow characteristics over specific types of terrain features. The report includes a discussion of relevant research requirements to improve understanding of wind characteristics in complex terrain in a generic fashion so that high wind areas within regions of complex terrain can be identified despite a lack of extensive measurements. 
Expected Progress During Next Reporting Period:

A final report will be published upon completion of the review of the draft report that was written in December 1977.

Reports and Publications: None. 
3.1.12 Coastal Zone Wind Energy (B3h)

Contract No.: EY-76-S-06-2344

University of Virginia

Department of Environmental Sciences

Charlottesville, Virginia 22903

Principal Investigators:

Michael Garstang (804)977-3733

Soronadi Nnaji

Roger A. Pielke

Contract Monitor:

Dennis L. Elliott (509)942-4762

objective:

To determine space and time characteristics of the

East Coast, Gulf Coast and near-shore regimes, through the use of an analytical model, which classifies climatological data and a mesoscale numerical model, which determines the integrated coastal effects for the dominant climatological classes.

Program Status:

This program was initiated in September 1975, funded for a second year in September 1977 and will continue through March 1979.

Progress During the Reporting Period:

Results of the first year's research, which used a two-dimensional mesoscale model, showed clearly that the large-scale velocity and stability fields and the land-sea temperature and roughness contrast exercised significant control on the location, size, and intensity of centers of high and low wind speeds on and near the East and Gulf Coasts. 
Work during this period has focused on classification of coastal windfields, using a midlatitude frontal-cyclone model. The purpose of the classification scheme is to determine the synoptic scale effects upon the windfield of the coastal baroclinic zone and to specify the dominant climatic conditions, which result in the local mesoscale circulations of the coast.

The climatological study based on 10 yr of data was completed for LaGuardia and Corpus Christi. Significant differences in the dominant weather regimes are noted for the two stations. Frontal-cyclone conditions are dominant for LaGuardia with highest wind speeds occurring behind the cold front for $26 \%$ of the time. Subtropical ridge conditions control the summertime flow of the west Texas coast. Mean wind speeds under these conditions are quite high but are subject to strong diurnal fluctuations. These types of summaries are now complete for 50 coastal stations.

The statistics of the climatological study are being used to examine the characteristics of the windfield in each of the major classes.

The climatology prescribes the input to the threedimensional model calculations. Figures $3-7$ and 3-8 show two examples of model calculations for a geostrophic wind of $210^{\circ}$ at $6 \mathrm{~m} \mathrm{sec}^{-1}$ and $030^{\circ}$ $6 \mathrm{~m} \mathrm{sec}^{-1}$. The left panels in the figures are for $10.2 \mathrm{~h}$, local solar time (11 a.m. EDT); the right for $15.2 \mathrm{~h}$ ( $4 \mathrm{p} . \mathrm{m}$. EDT). The wind vectors (upper panels) and wind speeds (m/sec times 10) are at $4 \mathrm{~m}$ above the surface for each 10 by $10 \mathrm{~km}$ square. Centers of relative maxima in speeds are 

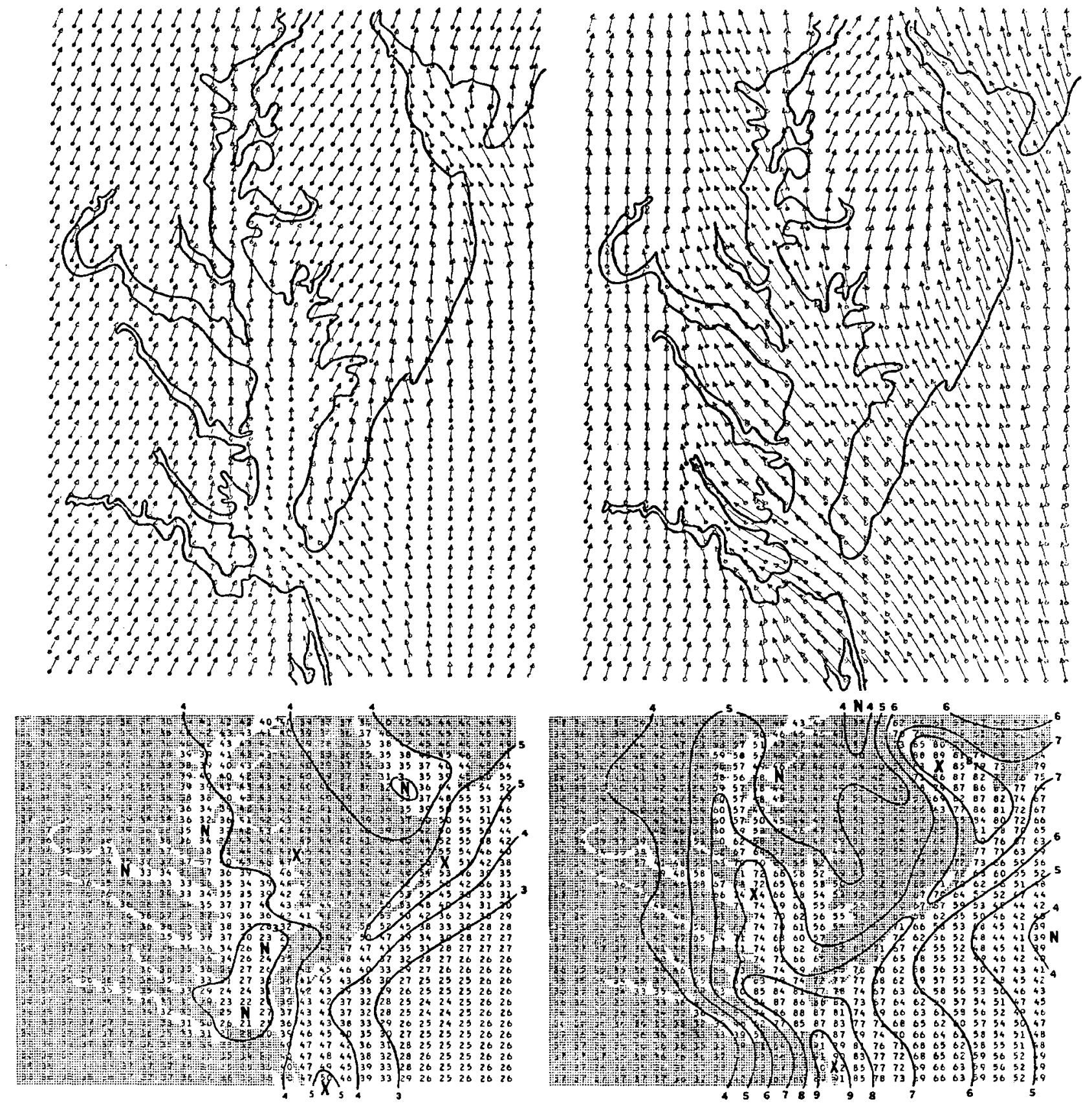

$10.2 \mathrm{~h}$

$v_{G}=210 \% 6 \mathrm{mps}$

$15.2 \mathrm{~h}$

FIGURE 3-7. Chesapeake Bay Area Windfield Predictions for a Relatively Cloud-Free, Summer Day with Geostrophic Wind, $210^{\circ} / 6 \mathrm{mps}$ 

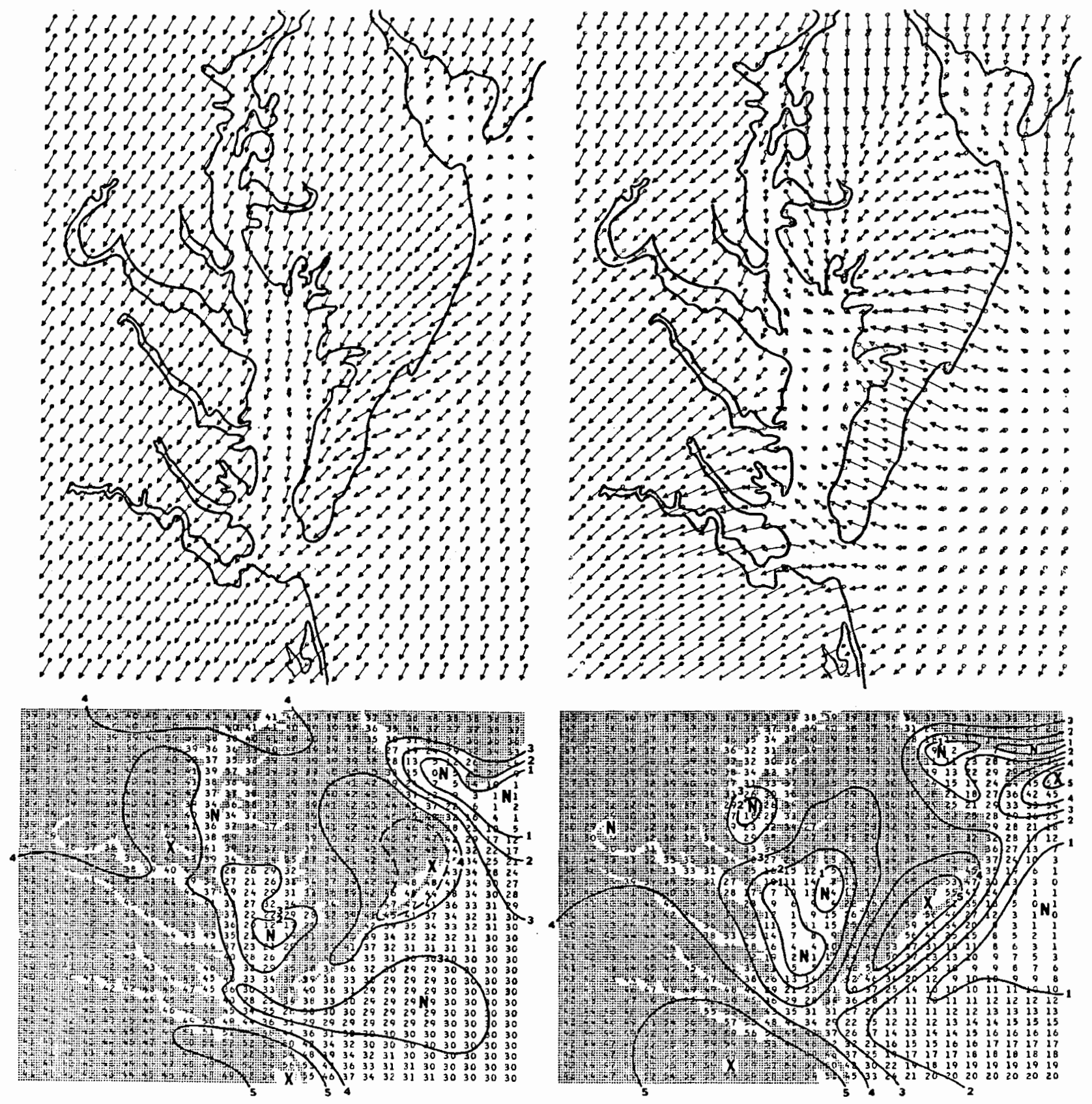

$10.2 \mathrm{~h}$

$V_{G}=030 \% / 6 \mathrm{mps}$

$15.2 h$

FIGURE 3-8. Chesapeake Bay Area Windfield Predictions for a Relatively Cloud-Free, Summer Day with Geostrophic wind, $030^{\circ} / 6 \mathrm{mps}$ 
marked with $X_{i}$ minima with $N$. Solid isolines are drawn for each $\mathrm{m} / \mathrm{sec}$. Centers of maxima and minima evolve in the windfield as the model responds to daytime heating over land and to the changes in roughness along the trajectory of the wind.

Expected Progress During Next Reporting Period:

The average annual and seasonal wind-power density $\left(\mathrm{w} / \mathrm{m}^{2}\right)$ for each $10 \times 10 \mathrm{~km}$ area of three coastal regions will be computed for the lowest $100 \mathrm{~m}$ of the atmosphere. The three $12 \times 10^{4} \mathrm{~km}^{2}$ regions are: the Chesapeake Bay, the panhandle of Florida and the Texas coast. The three-dimensional mesoscale model will be used in conjunction with the climatological study and the measured mean annual (1955-64) variations in the large-scale pressure field, atmospheric stratification and water vapor distribution, surface temperature, soil moisture, ocean temperature and certain derived parameters (e.g., surface albedo, roughness and soil conductivity) for each of the three areas. Model integrations will extend over the full 24-hr period for each of the dominant climatic regimes. Summation of the wind and power-density fields over the region for each regime will be compiled. Maps will be produced for each of four levels $(4,10,50$, $100 \mathrm{~m}$ ) and for the entire 100-m layer. The final result will display, for each of the three coastal regions chosen, the location and magnitude of the centers of maximum and minimum potential wind power by season and for the entire annual cycle.

The representativeness of the standard weather service wind measurements under each regime will be 
examined as will the validity of the various height-correction techniques in order to define the accuracy of the survey.

Reports and Publications:

M. Garstang, "Coastal Zone Wind Energy." Proceedings of the Third Wind Energy Workshop, Washington, D.C., September 19-21, 1977.

M. Garstang, C. I. Aspliden, S. Nnaji and

R. Pielke, Coastal Zone Wind Energy. RLO-2344-

76/77-5, Department of Environmental Sciences, University of Virginia, Charlottesville, VA 22903, January 1978 .

J. W. Snow, M. Garstang, R. Pielke and H. Cooper, "The Wind Potential of the Coastal Zone." Proceedings of the Third U.S. National Conference on Wind Engineering Research, Div. of Continuing Education, University of Florida, Gainesville, FL, February 1978. 


\subsubsection{Alaskan Wind Power Study (B3i)}

Contract No.: EY-76-S-06-2229

Geophysical Institute

University of Alaska

Fairbanks, Alaska 99701

Principal Investigator:

Tunis Wentink, Jr. (907)479-7607

Contract Monitor:

David S. Renne (509)942-4623

Objective:

To determine, by analysis and experiment, the potential of Alaska's wind power and its potential applications.

Program Status:

This program was initiated in May 1976 and is to continue through August 1978.

Progress During Reporting Period:

Wind speed (V) data from 80 Alaskan sites have been accumulated. The data have been curve-fitted to produce duration curves for 50 locations. Computations based on empirical function (Fl), the Weibull (F3) and Chi-2 or Rayleigh functions (F4) yielded over 640 duration curves for $F I$ and also for F3. These FI and F3 functions are shown to be almost equally useful for characterizing speed distributions. $F 3$ was used for many computations, but Fl was slightly superior to F3, because F3 can not incorporate calm data, while Fl has this capability.

A general relationship for the total power flux $(\mathrm{P} / \mathrm{A})$ of a wind distribution in terms of the mean 
wind speed $(\bar{V})$ was derived, based on $F 3$ and the shape factor $(k)$. This expression is:

$$
P / A=C_{0} f(k) \bar{V}^{3}=C_{0} \bar{v}^{3},
$$

with

$$
F(k)=\frac{\Gamma(1+3 / k)}{[\Gamma(1+1 / k)]^{3}}
$$

where $\mathrm{C}_{\mathrm{O}}$ is a unit-conversion factor.

From this the limitations on F4 are shown, since F3 with $\mathrm{k}=2$ becomes F4. In Alaskan wind-spectra, $\mathrm{k}$ varies from 1.1 to 2.6 , depending on location and month, with a mean for all sites of $1.8 \pm 0.3$. In general, from the previous equations,

$$
\frac{P / A(F 4)-P / A(F 3)}{P / A(F 3)}=\frac{6 / \pi}{f(k)}-1
$$

This expression is $\bar{V}$-independent.

Poor relationships usually exist between $\mathrm{k}$ and $\bar{v}$, but some marked and apparently related effects of seasons on $\mathrm{k}$ have been found. For instance, at some island sites $\mathrm{k}$ is independent of $\overline{\mathrm{V}}$ and the month. However at other locations with seasonal sea ice, $k$ varies according to the formation and disappearance of sea ice.

A detailed search of station histories led to the best estimates of average height of the $\bar{V}$ measurements at each location. All $\bar{V}$ data and constants defining the duration curves were scaled by a 
simple power-law relationship to standard heights of 10,30 and $50 \mathrm{~m}$. This scaling of the duration curve constants provides flexibility in scaling the wind spectra to any height of interest for WECS use.

The $P / A$ of the wind and the mean power for various WECS at the sites was computed; the $\mathrm{P} / \mathrm{A}$ and $\overline{\mathrm{P}}$ were tabulated for the individual months and for the seasons at the measurement and standard heights.

Expected Progress During Next Reporting Period:

The remaining time will be devoted to preparing the final report.

Reports and Publications:

T. Wentink, Jr., "Alaskan wind Power." Proceedings of the Third Wind Energy Workshop, Washington, D.C., september 19-21, 1977. 


\subsection{SITING METHODOLOGIES}

Site selection is crucial to the deployment of economically viable wind energy conversion systems (WECS). Without an adequate wind resource, a well-designed machine will not give satisfactory power output. The purpose of this program area is to devise strategies for selecting WECS sites, to develop the tools and techniques for implementing these strategies, and then to supply these tools and strategies to WECS users.

In the past, wind machines have been sited subjectively, i.e., by a general understanding of how terrain features affect airflow and by empirical guidelines drawn from this understanding. This method still remains a viable approach, particularly for low capital cost installations where extensive sitescreening and evaluation programs cannot be economically justified.

Information on the general characteristics of flow over terrain features and obstacles can be used both in the screening of a large area for potential WECS sites and in the final placement of a machine once the site is chosen. Relevant information on flow over obstacles, such as buildings and shelter belts, and small terrain features has been compiled (see Task C3a). To improve siting guidelines for small (total relief less than $300 \mathrm{~m}$ ) ridges and hills, flow over idealized models of these features has been studied in a wind tunnel (see Task $\mathrm{Clc}$ ). As a result of such studies, the general characteristics of flow over small hills and ridges are fairly well understood. The terrain shapes, which result in favorable wind characteristics at the summit, are as well identified as are those shapes, which lead to large vertical wind shears and flow separation.

Generic information gives useful guidance on the proper location of machines with respect to the local terrain features. 
However, estimates of machine power/output require specific wind characteristics, such as the mean wind speed. One way of obtaining the needed wind characteristics is to use information from nearby. wind recording stations. In areas of flat, homogenous terrain these data can be used from 50 to 100 miles from the recording station. But in other areas, the character of the wind can change significantly over a distance of a few miles.

In areas remote from measurement stations, or in regions with wide variations in wind speed, the shapes of well-exposed trees can indicate the local wind speed. In the 1930's, Putnam used qualitative relationships between tree shape and wind speed as part of the site-screening process. Currently, a re-evaluation of the role of trees and other biological indicators of wind speed is underway in an attempt to establish a quantitative relationship among wind speed, tree shapes and other biological indicators (see Task cld).

Useful relationships have been established between mean annual wind speed and two indicators of tree shape for conifers. Work is also underway to extend the techniques of biological wind prospecting to decidious trees and to examine the capability of remote sensing techniques to locate wind-stressed vegetation. A siting methodology, which will use this information in site screening, is being developed as part of this task.

Another way in which the wind characteristics over an area might be estimated is through numerical modeling. Numerical models provide an objective method for including the effect of terrain on airflow and interpolating wind data from locations where wind observations exist to places where measurements do not exist. It is natural, therefore, to include numerical modeling among the techniques that can be applied to the problem of site selection. 
Although it may be natural to consider numerical modeling as a site selection tool, it is not obvious that numerical modeling is a solution to the siting problem. The accuracy to which any model can represent flow over terrain depends upon the accuracy and density of the input data that is needed to characterize the initial and boundary conditions, the ability of the model to account for the complex interactions between the atmosphere and the surface of the earth and the spatial resolution of the model. An additional practical constraint is the computing speed of the model, since a large number of model simulations may be required to represent the wind climatology of an area.

The development of siting methodologies based on numerical techniques has been the object of both Task Cla and Clb. Task clb has concentrated on developing a methodology using both a primitive equation model and an objective windfield analysis scheme. In Task Cla, a methodology based on objective analysis techniques alone has been developed. Both of these methodologies are viewed as site-screening techniques: their purpose is to identify areas within a mesoscale region where the local wind has been enhanced by its interaction with the terrain. Because of limitations on the horizontal resolution of these models, they should not be used to predict wind characteristics at specific sites.

The purpose of Task C2a is to evaluate how accurately the numerical techniques can simulate the surface windfield over sections of complex terrain. In support of this task, the objective analysis techniques developed in Tasks cla and $\mathrm{clb}$ have been used to simulate flow over the island of Oahu. Preliminary results show that both techniques represent the general features of tradewind flow over the island quite well. The areas of high and low wind speeds correspond very well with observations. Additional work is underway to determine how 
accurately both the objective analysis methods and the primitive equation model estimate specific wind characteristics, such as wind speed and the wind probability distribution function, over the island. These models will also be applied to cases where the meteorology is more complicated and the boundary conditions less accurately known than the island of Oahu. The result of these studies will be an improved understanding of how numerical techniques can be applied to the problem of site selection.

Flow over terrain may also be modeled by placing a scale model of the terrain into a suitably designed wind or water tunnel. Flow over the model will be similar to flow over the actual terrain if there is dimensional similarity between the model and the terrain and if the flow over the model is dynamically similar to the flow in the atmosphere. Dimensional similarity can be achieved, as long as the modeled area remains small. Exact dynamic similarity, however, is impossible. Nevertheless, if the modeled region is less than a few tens of kilometers in size and if the portion of the atmosphere to be studied is of the lowest few hundred meters, a reasonable approximation of dynamic similarity can be achieved.

As part of Task Clc, flow through the Rakaia Gorge in New Zealand has been modeled in a wind tunnel. For the wind direction of greatest wind-power potential, wind tunnel measurements were compared with field measurements at numerous locations. The agreement was very good. Additional studies of physical modeling will be conducted in FY-1979. The Kahuku Point area of Oahu is being modeled, and the results will be compared with detailed field measurements made by researchers from the University of Hawaii. The results of the Rakaia Gorge studies, as well as from other experiments, suggest that physical modeling can be a useful tool for examining the flow over small sections of terrain. 
Regardless of the techniques used to screen areas for potential WECS sites, the decision to install a WECS at a particular site will depend upon the results of economic and performance analyses. The accuracy of these analyses depends upon the accuracy to which the wind characteristics are known. The only accurate method of determining these characteristics at a specific site is through onsite measurements. Three reports that discuss measurement systems that can be used in various stages of the site selection process have been published (see Task $\mathrm{C} 3 \mathrm{c})$. One report recommends an instrumentation system for providing the wind data needed to evaluate a particular site for a large machine. The other two documents discuss a data logging system that could be used as part of a wind prospecting instrument.

Work that is planned for the coming year in the measurement area includes:

- A report covering data analysis procedures and measurement practices aimed at small machine users.

- An evaluation of measurement-based site-screening methodologies.

- Testing of a wind prospecting instrument.

- An examination of low-cost wind-measuring equipment. 


\subsection{PROGRESS IN TECHNICAL TASKS}

4.1.1 Wind Power Studies (Cla)

Contract No.: UCRL-50034-76

Lawrence Livermore Laboratory

University of California

Livermore, CA 94550

Principal Investigator:

Christine A. Sherman (415)422-8986

Contract Monitor:

William T. Pennell (509)942-4620

Objective:

To develop and demonstrate a methodology for the assessment of wind power in hilly or mountainous areas.

\section{Program Status:}

This program started at the beginning of FY-1976 and will continue into FY-1979.

Progress During Reporting Period:

Work during the last year has concentrated on processing the data from the oahu field-measurement program and on verification of the siting methodology and the numerical techniques that make up the methodology. A data set has been generated for Oahu covering the period 1 August 1976 to 31 July 1977. Data acquisition was completed by the end of July, and a second data base covering the period 1 August 1977 to 31 July 1978 is being prepared. A verification of the principal components analysis (PCA) technique has been completed for a San Francisco Bay area data set. Procedures for verifying the objective analysis technique 
(MATHEW) has been drafted. Both MATHEW and the PCA will be verified for Oahu and other data sets obtained in areas exhibiting more complex climatologies, such as the San Francisco Bay area. The Oahu surface wind data set for the period 1 August 1976 to 31 July 1977 can be obtained from Lawrence Livermore Laboratories. A report has been issued, which summarizes the data set. Other reports describe the results of the PCA verification and the documentation of the PCA computer code.

Expected Progress During Next Reporting Period:

Verification of MATHEW and the siting methodology that combines MATHEW and PCA will be completed. The 2-yr Oahu data base will be documented and released.

Reports and Publications:

Christine A. Sherman, "A Mass-Consistent Model for Wind Fields Over Complex Terrain." Journal of Applied Meteorology, Vol. 17 No. 3, 312-319, March 1978.

Donald M. Hardy, "Numerical and Measurement Methods of Wind Energy Assessment." Proceedings of the Third Wind Energy Systems Workshop, Washington, D.C., September 19-21, 1977. 
4.1.2 Development of a Wind Energy Site Selection

Methodology (C1b)

Contract No.: EY-76-C-06-2440

Science Applications, Inc.

1200 Prospect Street

P. O. Box 2351

La Jolla, CA 92038

Principal Investigator:

Richard M. Traci (714)459-0211

Contract Monitor:

William T. Pennell (509)942-4620

Objective:

To develop, verify and demonstrate a wECS siting methodology for complex terrain. The methodology is based on two mathematical windfield models that are utilized to define the wind characteristics of sites within the region. One of the models is an objective analysis code and the other is a primitive equation model.

Program Status:

The program is in the final phase of a 3-yr effort that began in May 1975 and is scheduled for completion in september 1978.

Progress During the Reporting Period:

Progress during the past year can be summarized as follows :

- streamlining SIGMET, the primitive equation model, and NOABL, the objective analysis scheme codes, to operational status and delivery to PNL

- preparing and delivering "Preliminary Users Manuals for SIGMET and NOABL" 
- completing graphics output packages for SIGMET and NOABL

- completing SIGMET code development studies

- completing terrain conformal NOABL code development studies

- beginning model verification studies.

The items mentioned above complete the development of the windfield models and the methodology for applying them. The next step is to test certain features of the models and to verify their accuracy. Some initial verification studies have been completed for the vicinity of the White sands Missile Range (WSMR) in New Mexico (see Figure 4-1).

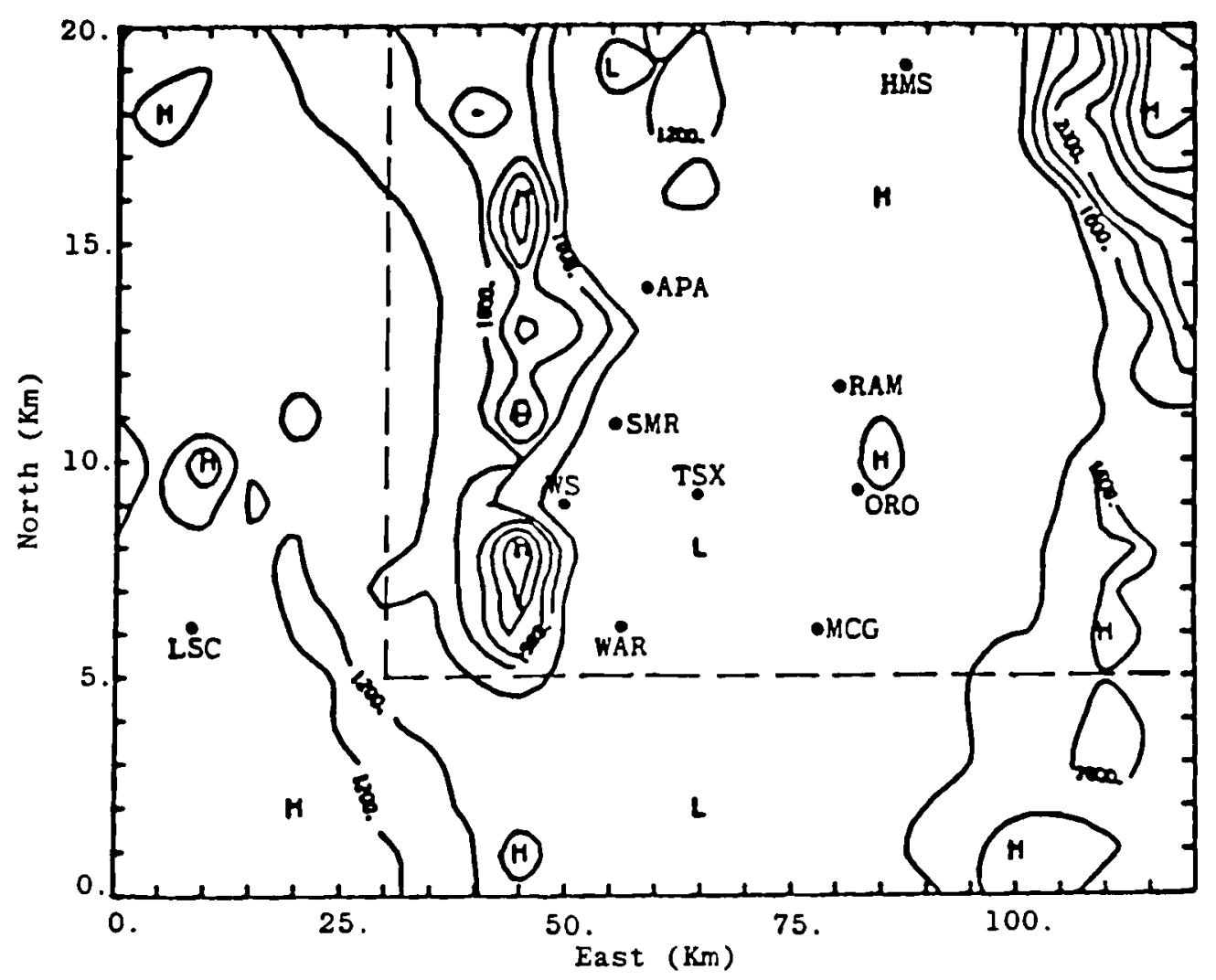

FIGURE 4-1. Contour Map of White Sands Missile Range with Locations of Available Wind Data 
Figure 4-1 shows a contour map of the area and the locations where wind are available. The objective analysis code NOABL was run on the smaller region enclosed by the dotted lines. Table 4-l shows a matrix of input and verification data that was used in the study.

TABLE 4-1. Matrix of Input and Verification Data

\begin{tabular}{|c|c|c|c|c|c|c|c|c|}
\hline & 1 & 2 & 3 & 4 & 5 & 6 & 7 & 8 \\
\hline CASE & TSX & ORO & WAR & SHR & LSC & RAM & APA & HWS \\
\hline 1 & $\mathbf{u}$ & $u$ & $u$ & $u$ & $u$ & $\mathrm{u}$ & $\mathbf{u}$ & $u$ \\
\hline 2 & $\mathbf{u}$ & $x$ & $x$ & $\mathbf{x}$ & $u$ & $x$ & $\mathbf{u}$ & $u$ \\
\hline 3 & $x$ & $\mathbf{x}$ & $\mathbf{x}$ & $\mathbf{u}$ & $u$ & $x$ & $\mathbf{u}$ & $u$ \\
\hline 4 & $u$ & $x$ & $x$ & $x$ & $u$ & $x$ & $x$ & $u$ \\
\hline 5 & $u$ & $x$ & $x$ & $x$ & $\mathbf{u}$ & $x$ & $u$ & $x$ \\
\hline 6 & $x$ & $u$ & $x$ & $x$ & $\mathrm{u}$ & $x$ & $x$ & $u$ \\
\hline 7 & $x$ & $\mathbf{x}$ & $x$ & $u$ & $\mathbf{u}$ & $x$ & $\mathbf{x}$ & $x$ \\
\hline 8 & $u$ & $x$ & $x$ & $x$ & $\mathbf{u}$ & $x$ & $x$ & $x$ \\
\hline 9 & $u$ & $\mathbf{x}$ & $x$ & $x$ & $x$ & $x$ & $x$ & $x$ \\
\hline 10 & $x$ & $x$ & $x$ & $x$ & $\mathbf{u}$ & $x$ & $x$ & $x$ \\
\hline
\end{tabular}

u: data station used

$\mathbf{x}$ : unused

Figure 4-2 is a scatter diagram for case 6 of the study. The agreement between the simulated and observed wind speeds is quite good. The mean deviation, $\mathrm{d}$, for this case if $-0.86 \mathrm{~m} \mathrm{~s}^{-1}$ $\mathrm{d}=\frac{1}{\mathrm{~N}}{ }_{i=1}^{\mathrm{N}} \quad \mathrm{q}_{\text {calc }}-\mathrm{q}_{\text {obs }} i$ and the correlation coefficnet, $r$, is 0.72 . This example is one of 
the better ones; nevertheless, the agreement between the observed and simulated wind speeds for all the cases listed in Table 4-1 were good, except for case 7. Excluding case 7, d was less than $2.6 \mathrm{~m} \mathrm{~s}^{-1}$ and $r$ was greater than 0.63 for all of the cases shown in the table.

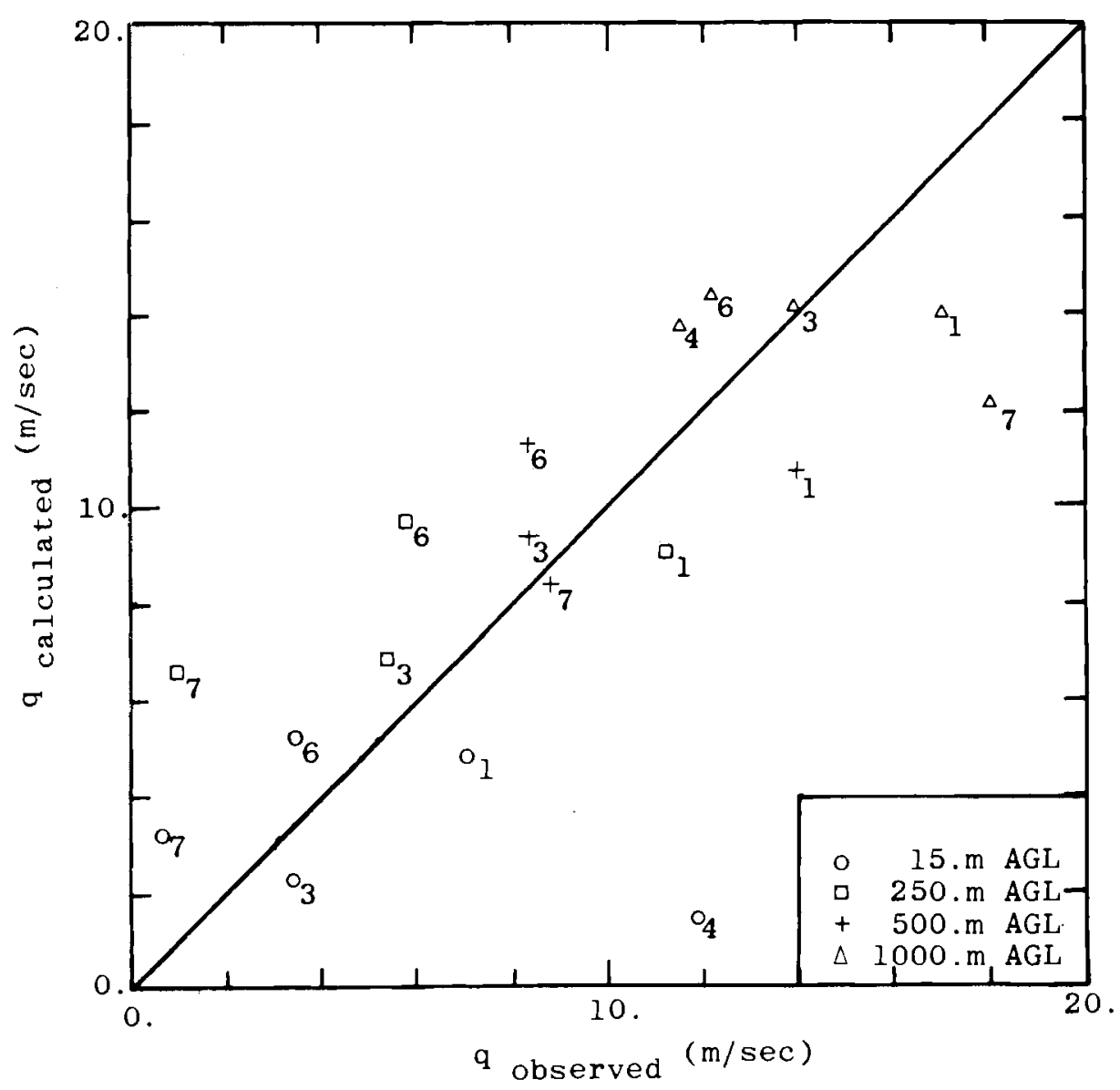

FIGURE 4-2. Comparison of Calculated to Observed Wind Speeds (stations ORO (2), LSC (5) and HMS (8) were used in initialization)

Wind speed observations were available only at valley locations in the WSMR area; therefore, how well the model would perform in the highlands 
is not known. Thus, a final judgment on the capabilities of NOABL in mountainous terrain must await further verification studies in regions where the observed data are more randomly distributed.

Expected Progress During Next Reporting Period: The model verification program will be accelerated during the next reporting period. The program consists of detailed comparisons of windfield model results with available field-test data sets. The verification studies for one of the data sets (Oahu) should be completed and similar studies should be initiated in the next six months for a second data set. The studies for each site will include:

- data set collection and selection (in conjunction with PNL)

- windfield simulations: 50 to 100 NOABL simulations, 3 to 5 SIGMET simulations, results analysis, and data comparison.

Reports and Publications:

R. M. Traci, G. T. Phillips, P. C. Patnaik, and B. E. Freeman, Development of a Wind Energy Site Selection Methodology. RLO/2440-77/11, Science Applications, Inc., Report No. SAI-77-776-LJ, June 1977.

R. M. Traci, G. T. Phillips, P. C. Patnaik, and B. E. Freeman, "The Utility of Mathematical Windfield Models in a WECS Siting Methodology: A Case study." Proceedings of the Third Wind Energy Workshop, Washington, D.C., September 19-21, 1977. 


\subsubsection{Sites for Wind Power Installations ( $\mathrm{Clc}$ )}

Contract No.: EY-76-S-06-2438

Colorado State University

Department of Civil Engineering

Fort Collins, CO 80523

Principal Investigators:

R. N. Meroney (303) 491-8572

V. A. Sandborn (303) 491-8551

Contract Monitor:

William T. Pennell (509)942-4620

Objective:

To verify wind-tunnel techniques for determining the influence of topography on the near-surface windfield.

Program Status:

This program was initiated in June 1975 and will continue through May 1979.

Progress During Reporting Period:

A laboratory wind tunnel was used to study airflow over various terrain features in order to locate optimum sites that have high wind speeds and low turbulence. The study assesses the effects of surface roughness, slope, topographic profile shape, stratification, and upstream velocity on the wind characteristics at potential WECS sites. During the final portion of this research period, measurements were completed and reports prepared concerning airflow perturbations produced by topography.

Through a series of experiments that varied the slopes of the windward and leeward sides of a 
ridge, the influence of these parameters on separation and wind speedup has been identified.

Separation can occur at two places on a ridge: at the base of the ridge and just downstream of the crest. The dimensions of the separation region downstream of the crest depend on the strength of the separation eddy. For relatively gentle downwind slopes, only weak eddies can develop, and the separation zone occurs only near the summit. The effect of the slope of the downwind side ( $h / L_{d}$, where $h$ is the ridge height and $L_{d}$ is the horizontal extent of the downwind slope) on the mean velocity field is illustrated in Figure 4-3 by the vertical velocity profiles at different locations downwind of the hills. For all cases, the ratios of the height of the ridge to the boundary-layer thickness and the height of the ridge to the longitudinal scale of turbulence* were 0.1 and 0.5 , respectively. In the atmosphere this would correspond to a hill about $100 \mathrm{~m}$ high. As can be observed, the greatest speedup over the hill crest occurs for $\mathrm{h} / \mathrm{I}_{\mathrm{d}}=1 / 6$. This is the largest value of $\mathrm{h} / \mathrm{L}_{\mathrm{d}}$ for which separation is not observed. once flow separation occurs, a dramatic decrease in speedup effects is observed.

Experimental evidence shows that for neutrally stratified flows, separation at the crest of a ridge depends primarily on the downwind slope $\left(\mathrm{h} / \mathrm{L}_{\mathrm{d}}\right)$ and $\mathrm{h} / \mathrm{L}_{\mathrm{u}}$, where $\mathrm{h} / \mathrm{L}_{\mathrm{u}}$ is the ratio of the hill height to longitudinal turbulence scale. Figure 4-4 shows the functional relationship

* The longitudinal scale of turbulence is roughly the size of the dominant turbulent eddies measured along the direction of the mean wind. 


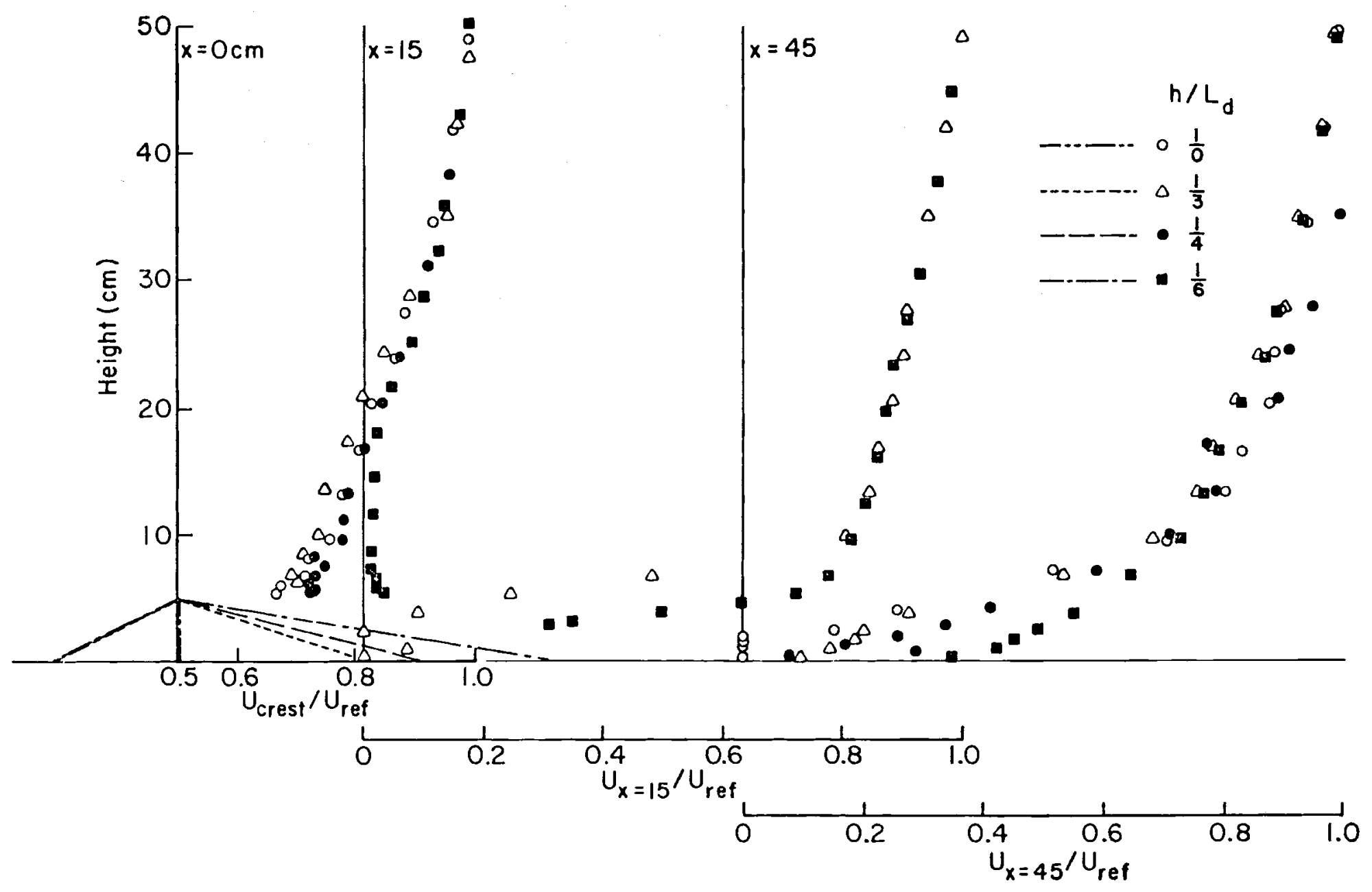

FIGURE 4-3. Occurrence of Flow Separation Over Triangular Model Hills 


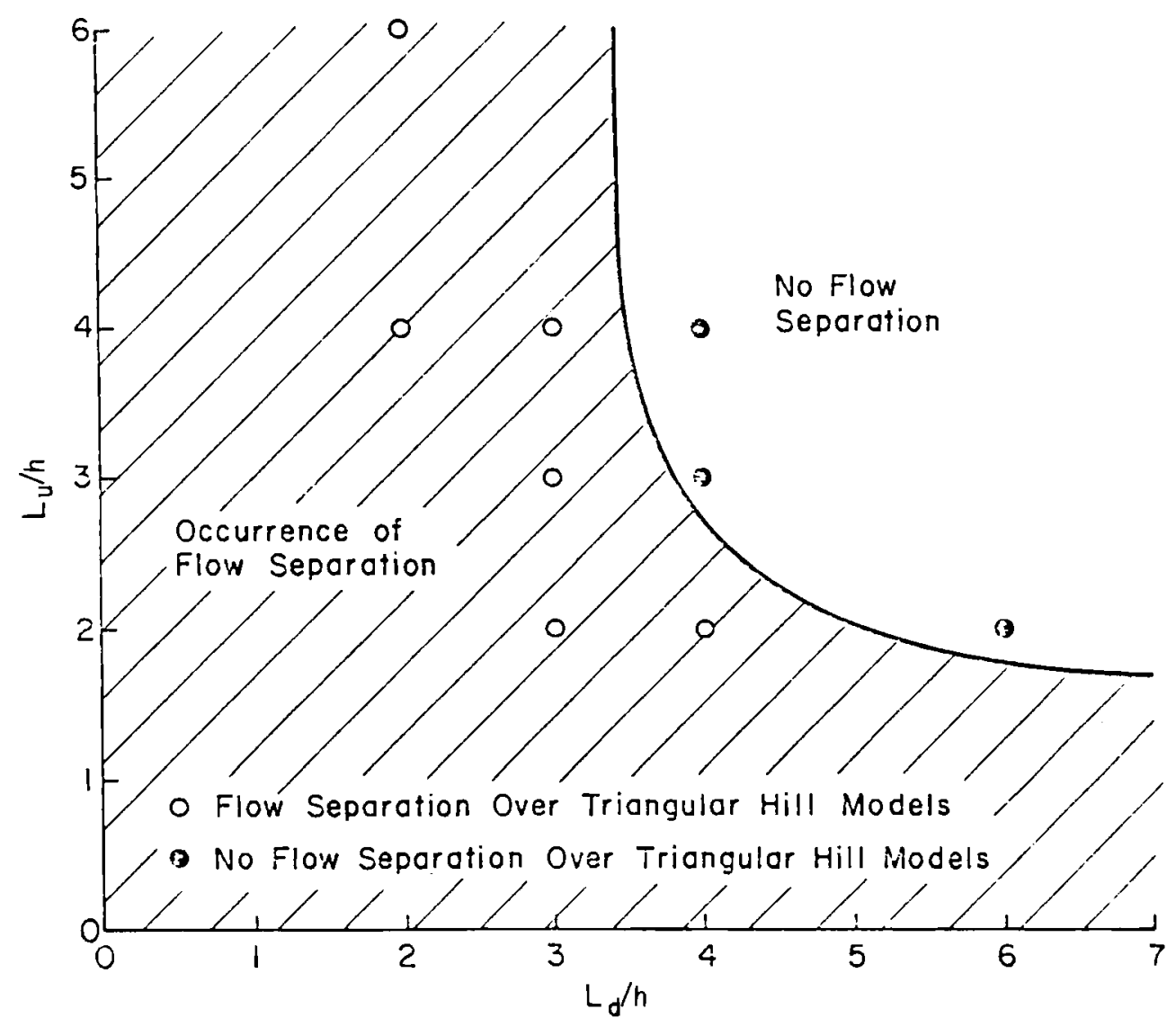

FIGURE 4-4. Functional Relationship Between $\mathrm{h} / \mathrm{L}_{\mathrm{d}}$ and $\mathrm{h} / \mathrm{L}_{\mathrm{u}}$ and the Occurrence of Flow Separation for Triangular Ridges

between $h / L_{u}, h / L_{d}$, and the occurrence of flow separation for triangular ridges. Since the greatest speedup occurs just before separation, this figure identifies the ridge profiles that exhibit the highest speedup effects.

Measurements over a series of three-dimensional hills for neutral stability did not produce speedup effects as large as similar section ridges oriented perpendicular to the wind. Speedup ratios at the crest of symmetrical hills were about $40 \%$ lower 
than for similarly shaped ridges. On the hill slopes, differences in the speedup ratio were often larger.

Both measurements and theory suggest that when compared to neutral conditions, mildly stable atmospheric stratification decreases the amount of speedup at the crest of a ridge. Unstable stratification, on the other hand, has the opposite effect. These conclusions apply only if an elevated inversion is not observed above the ridge crest. When airflow is constrained to move between a ridge and an elevated inversion, the ratio of the height of the ridge to the height of the inversion becomes an additional parameter.

Expected Progress During Next Reporting Period: An additional test of physical modeling as a sitescreening technique will be undertaken in the next year. A 1:3840 scale model of the Kahuku Point region of the island of oahu has been constructed. The windfield as simulated by the wind tunnel model will be compared to available field measurements.

Reports and Publications:

R. N. Meroney, "Prospecting for Wind Energy." CEP 77-78RNM65, 1978 ISES, Solar Diversification Annual Meeting, Denver, CO, August 28-31, 1978. Reiner Boumeester, "The Influence of Hill Shape on wind Characteristics Over Two-Dimensional Hills." Proceedings of The Third Wind Energy Workshop, Washington, D.C., September 19-21, 1977. 
V. A. Sandborn, "Sites for Wind-Power Installation." Paper presented at Wind Energy Symposium, University of Regina, Regina, Alberta, Canada, October 17, 1977.

V. A. Sandborn, "Placement of Wind-Power Systems." Paper presented at Wind Energy Symposium, University of Regina, Regina, Alberta, Canada, October 17, 1977.

V. A. Sandborn, "Atmospheric Boundary Layer Model for wind Power Sites." Paper presented at a short course on wind Energy Conversion Machines, University of Tennessee Space Institute, Tullahoma, Tennessee, November 28 - December 2, 1977.

M. A. Ridger, "Measurements of Mean and Longitudinal Turbulent Velocities over Varying Hill Shapes." M.S. Thesis, Colorado State University: Ft. Collins, CO, August, 1977. 
Contract No.: EY-76-S-06-2227

Oregon State University

Atmospheric Sciences Department

Corvallis, OR 97331

Principal Investigator:

E. Wendell Hewson (503)754-4557

Contract Monitor:

William T. Pennell (509)942-4620

Objective:

To calibrate various indices of wind effects on vegetation in terms of wind characteristics.

Program Status:

This is the second year of a program that began in July 1976.

Progress During Reporting Period:

Work has continued on calibrating the indices of wind effects that were identified in the first year of this study. Three indices have been calibrated in terms of the annual mean wind speed at 24 locations in the Pacific Northwest. At each of these locations a wind record of at least one year is available. Preliminary calibrations have been made on three indices:

- Griggs-Putnam Index: a subjective scale of tree deformations.

- Deformation Ratio: an indicator of windinduced crown asymmetry and trunk defection.

- Compression Ratio: a measure of the influence of wind on the formation of reaction wood and the resulting eccentric radial growth. 
The definitions of the Griggs-Putnam Index and the deformation ratio are given in Figures 4-5 and 4-6. The compression ratio is defined as the ratio of the thickness of the lee-side growth ring for a given year divided by the thickness of the windward-side growth ring for that same year.

PREVAILING WI ND

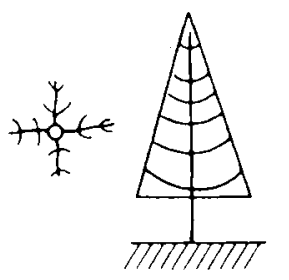

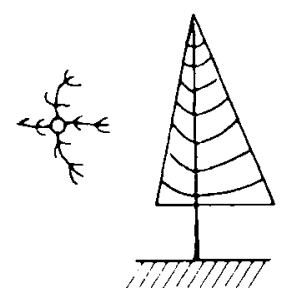

11 SLIGHT FLAGGING

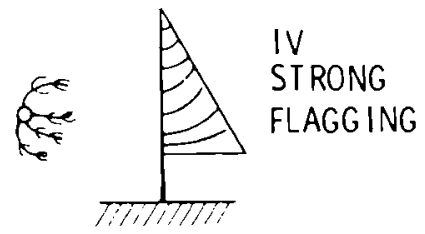

VI

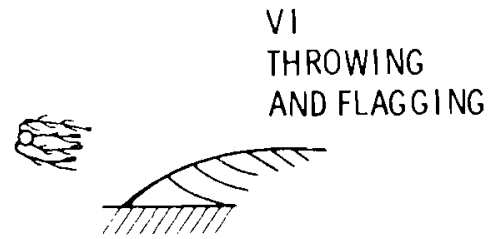

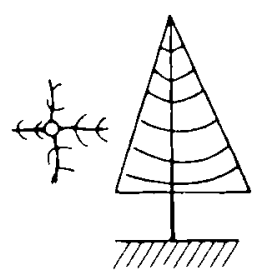

BRUSHING ONLY
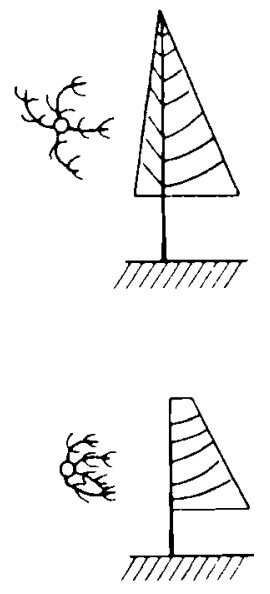
AND FLAGGING

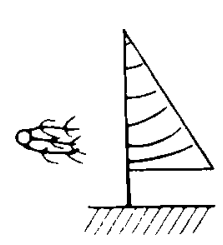

$\mathrm{V}$

CLIPPING

III MODERATE

FLAGGING

VII

EXTREME

FLAGG ING

FIGURE 4-5. Griggs-Putnam Index 

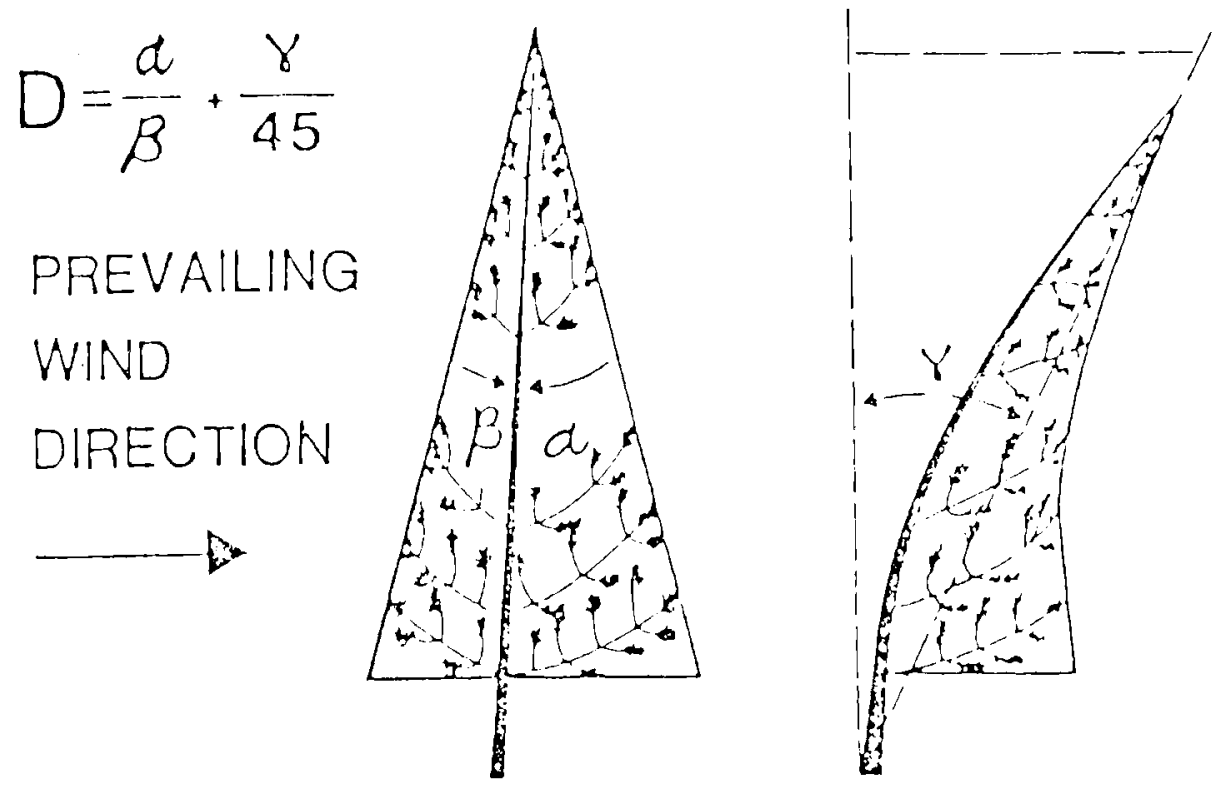

FIGURE 4-6. Deformation Ratio

Table 4-2 summarizes the relationships between the three indices and annual mean wind speed. Up to the present time the study has concentrated on Douglas-fir (Pseudotsuga menziesii) and Ponderosa Pine (Pinus ponderosa). Thus, preliminary calibrations are applicable to only these species. In Table 4-2, the relationships between G (GriggsPutnam Index), D (Deformation Ratio) and C (Compression Ratio) and the annual mean wind speed are summarized. For each relationship the correlation coefficient $(r)$, the mean error (ME), and the percentage of time the prediction error exceeds 25\% $\left(\mathrm{P}_{25}\right)$ are also shown. Table 4-3 and Figures 4-7 and 4-8 summarize the relationships in tabular and graphical form. 
TABLE 4-2. Relationships Between $\overline{\mathrm{V}}$ and Index Values

\begin{tabular}{|c|c|c|c|c|c|}
\hline Index & & Relationship & $r$ & $\operatorname{ME~(o~}$ & $\mathrm{P}_{25}(\mathrm{z})$ \\
\hline G & $\overline{\mathrm{V}}$ & $=1.05 \mathrm{G}+2.72$ & .90 & 14 & 8 \\
\hline D & $\overline{\mathrm{V}}$ & $=0.9 D+3.00$ & .88 & 15 & 21 \\
\hline $\mathrm{C}$ & $\bar{v}$ & $=3.6 \mathrm{C}+0.32$ & .67 & 22 & 32 \\
\hline
\end{tabular}

TABLE 4-3. Relationship Between the Griggs-Putnam Index (G) and the Annual Mean Wind speed $(\bar{v})$ in $\mathrm{m} \mathrm{sec}^{-1}$.

$\begin{array}{lc}G & \overline{\mathrm{V}} \\ 0 & <3.3 \\ 1 & 3.3-4.2 \\ 2 & 4.3-5.1 \\ 3 & 5.2-6.2 \\ 4 & 6.3-7.5 \\ 5 & 7.6-8.5 \\ 6 & 8.6-11.0 * \\ 7 & >11.0 *\end{array}$
* Estimated since data are not available for these
speed ranges. 


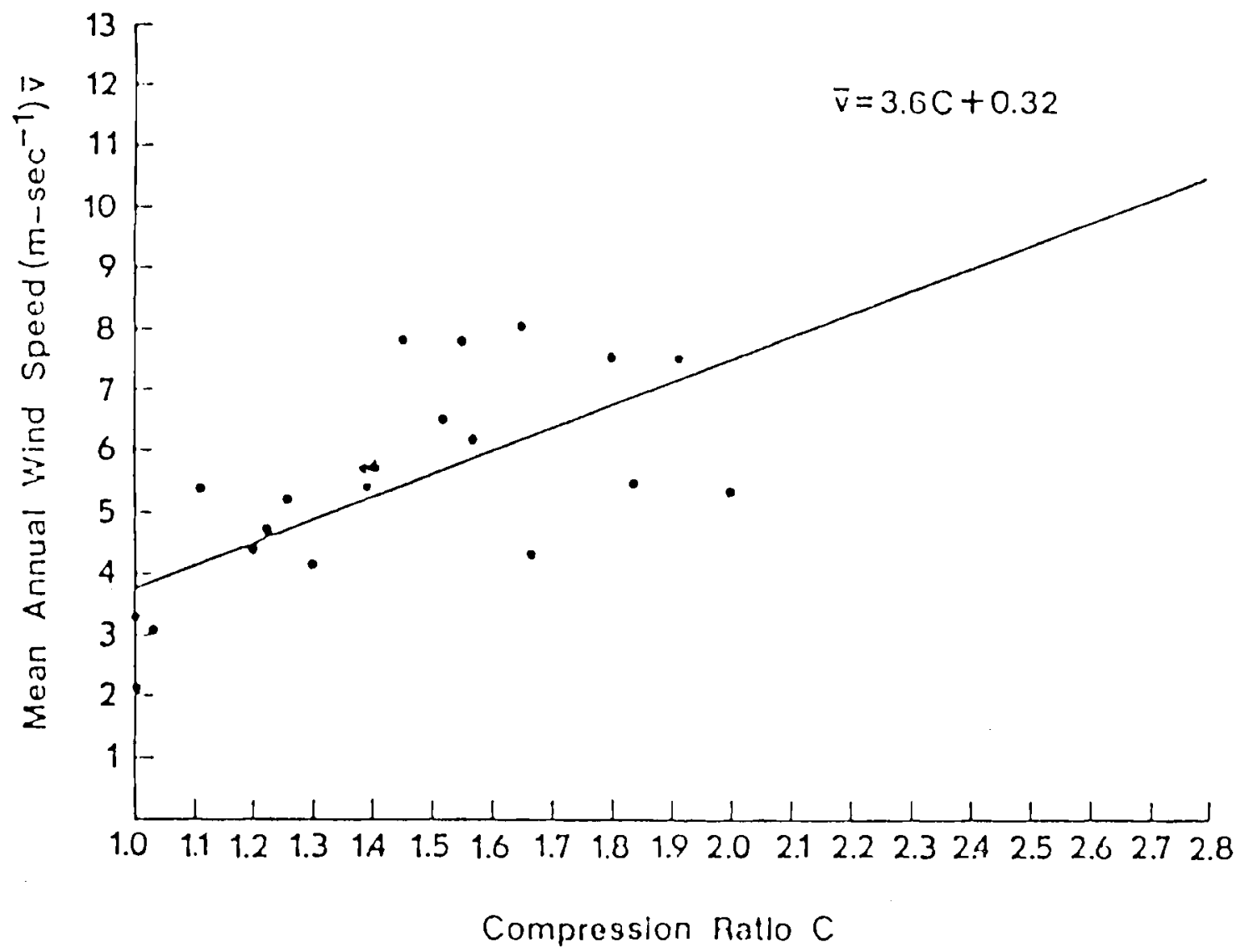

FIGURE 4-7. Relationship Between Compression Ratio and the Mean Annual wind Speed for the Coniferous Trees Studied

Results to date show that wind-deformed conifers can be used to obtain useful estimates of wind speed and thus provide a powerful site-screening tool.

Expected Progress During Next Reporting Period:

During the next year, research will focus on extending these techniques to other coniferous species and to deciduous trees. Work is also proceeding in developing techniques for identifying wind-deformed vegetation from aerial photographs. 


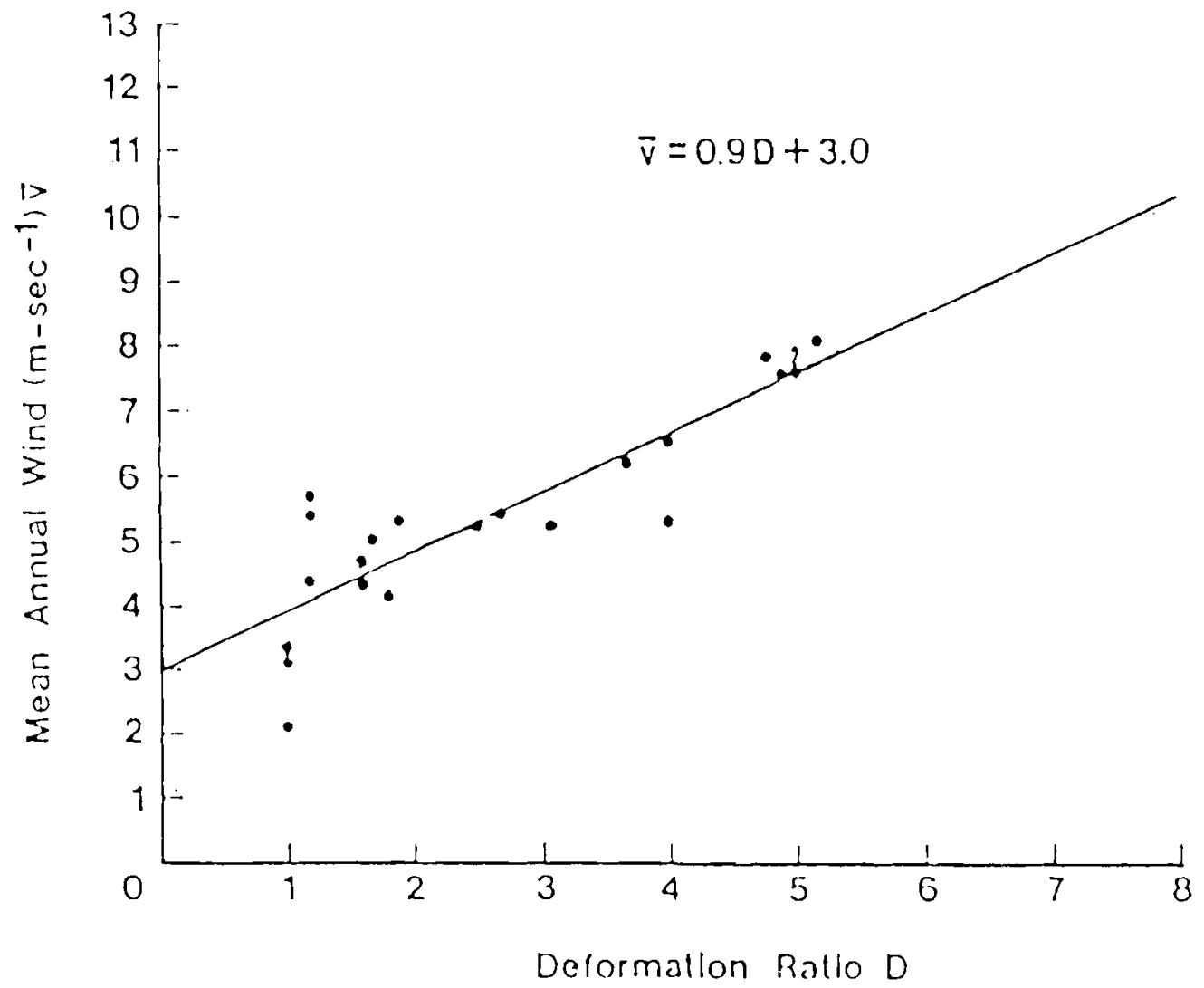

FIGURE 4-8. Relationship Between the Deformation Ratio and the Mean Annual Wind Speed for the Coniferous Trees Studied

Reports and Publications:

E. W. Hewson and J. E. Wade, "Biological Wind

Prospecting." Proceedings of The Third Wind Energy Workshop, Washington, D.C., September 19-21, 1977. 


\subsubsection{Assessing the Local WindField (Cle)}

Contract No.: EY-76-C-06-2441

AeroVironment

145 Vista Avenue

Pasadena, CA 91107

Principal Investigator:

Paul B. MacCready, Jr. (213) 449-4392

Contract Monitor:

Ronald K. Hadlock (509)942-4821

objective:

To observe, with dual doppler acoustic radar systems, the three-dimensional airflow over complex terrain features to an altitude of $100 \mathrm{~m}$ above the earth's surface.

Program Status:

This project was completed in August 1977. The final report has been published.

Progress During Reporting Period:

Data describing the wind profiles from the surface to $100 \mathrm{~m}$ at two locations in the mountains near Pasadena, California, were obtained in June 1977. These data were analyzed and the results summarized.

The project demonstrated that the doppler acoustic radar described in the report was not capable of reliably providing wind data of sufficient accuracy to be useful for WECS siting.

Reports and Publications:

P. B. MacCready, Jr., "Assessing the Local Wind Field for Siting." Proceedings of The Third Wind Energy Workshop, Washington, D.C., September 19-21, 1977. 
4.1.6 Technique for Siting Using Statistics on Primitive Equation Model Results (Clf)

Contract No.: EY-76-C-06-2445

Research Triangle Institute

Geosciences Department

Research Triangle Park, NC 27711

Principal Investigator:

Fred M. Vukovich (919)541-6946, Ext. 2657

Contract Monitor:

Larry L. Wendell (509)942-4626

Objective:

To determine the feasibility of using historical

wind data from a synoptic weather station, together with simulated windfields in the vicinity of that station, to predict the wind distribution at nearby locations where wind data are not available.

Program Status:

This project started September 20, 1977 and continued through December 1977. The final report for this project is in printing.

Progress During Reporting Period:

A reasonably comprehensive error analysis was performed to determine the sources of the discrepancies between the predicted and observed wind characteristics. Results of the analysis indicated about 5 \% of the total discrepancy was attributable to the statistical modeling procedures. The remaining $95 \%$ was accounted for by two major factors:

- Approximately $60 \%$ of the total discrepancy resulted from Lambert field data, which were 
1-min observations recorded to the nearest whole knot and nearest $10^{\circ}$.

- The remaining 35\% of the total discrepancy occurred because the actual RAPS data and the simulated data from the hydrodynamic model did not yield comparable parameter estimates in the statistical models.

The 1-min data from one RAPS station were used to produce 1 -hr average values for comparison with $1-m i n$ values rounded to the nearest whole knot and nearest $10^{\circ}$. The correlation between these to data strings from the same station was 0.845 . The conclusions of this study suggest that the proposed technique for developing wind statistics in remote locations is feasible, provided reasonably accurate simulation data can be produced. This qualification becomes extremely important when the area of interest is in terrain more complex than the relatively flat terrain around St. Louis. Results from other techniques under development in the WCPE need to be examined before work of this type is resumed.

Expected Progress During Next Reporting Period: The contract is closed.

Reports and Publications:

F. M. Vukovich and C. A. Clayton, "On a Technique to Determine Wind Statistics in Remote Locations." Proceedings of the Third Wind Energy Workshop, Washington, D.C., September 19-21, 1977. 
4.1.7 The Effect of Atmospheric Density Stratification on Wind-Turbine Siting (Clg)

Contract No.: $\mathrm{EY}-76-\mathrm{C}-06-2443$

Poseidon Research

11777 San Vincente Blvd.

Suite 64

Los Angeles, CA 90044

Principal Investigator:

Steven C. Crow (508)826-5543

Contract Monitor:

William T. Pennell (509)942-4620

Objective:

To study the effect of atmospheric stability on wind-turbine siting through the use of a simple numerical model. The model is used to determine the effect of stability and terrain shape on the location of areas of high wind velocity. Regions with adverse pressure gradients, which are expected to be poor wind-turbine sites, are also identified.

Program Status:

The program is a 15-mo effort that was initiated in september 1976 and is now complete. The final report for this project is in printing.

Progress During Reporting Period:

Numerical codes for density-stratified airflow over two-dimensional and three-dimensional mountains were developed. Computations were performed for a wide selection of atmospheric conditions. Parametric studies were performed to evaluate the sensitivity of the near-ground airflow as a function of ambient wind speed and direction, mountain height and shape, height of the troposphere, 
stratification in the troposphere, and different inversion conditions. For the three-dimensional computations, mountains of Gaussian form were considered.

For flow over both two-dimensional and threedimensional mountains in neutral atmospheric conditions, the wind-speed maximum is located at the peak of the mountain if no temperature inversion is present above the mountain. During stable atmospheric conditions and neutral conditions with an inversion, the wind-speed maximum moves to the lee side of the mountain. The location of the wind speed maximum is a function of the stratification in the troposphere and the freestream wind speed.

Possible regions of flow separation occur on the windward as well as on the leeward side of the mountain. On the leeward side of the mountain they occur just downstream of the location of maximum wind speed.

Expected Progress During Next Reporting Period: This contract is closed.

Reports and Publications:

K. G. Agopian and S. C. Crow, The Effect of Atmospheric Density Stratification on Wind Turbine Siting. Progress Report for the period October 1976 through March 1977, Poseidon Research, Los Angeles, CA, 1977.

K. G. Agopian, "The Effect of Atmospheric Density Stratification on wind Turbine Siting." Proceedings of the Third Wind Energy Workshop, Washington, D.C., September 19-21, 1977. 
4.1.8 Plan Site Screening Technique Verification and

Pacific Northwest Laboratory

Richland, WA 99352

Principal Investigator:

William T. Pennell (509)942-4620

Objective:

To evaluate the accuracy of numerical sitescreening techniques.

Program Status:

The evaluation criteria, data sets, and procedures have been developed and a plan for the verification exercises has been produced.

Progress During Reporting Period:

The decision was made to evaluate the three windfield models that have been developed for DOE as part of the Federal Wind Energy Program. These are the objective analysis (NOABL) and primitive equation code (SIGMET) developed by SAI and the objective analysis code (MATHEW) developed by LLL. These codes will be verified by comparison to field data from the report regions. Two of the field data sets will be for the island of Oahu, Hawaii and for the Nevada test site. The third data set was planned to be the Vanderberg Air Force Base; however, it may be replaced by a more current set.

A meeting on verification procedures was held in April and the procedures were approved by the participants. Model computations are underway for Oahu. 
Expected Progress During Next Reporting Period:

Model verification for the Oahu data set will be completed and a preliminary report will be issued. Verification will proceed on the next two data sets.

Reports and Publications:

None. 
4.1.9 Wind Turbine Generator Siting Techniques Relative to Three-Dimensional Terrain Features (C3a)

Contract No.: EY-76-C-06-2443

FWG Associates, Inc.

R.R. 3, Box 331

Tullahoma, TN 37388

Principal Investigator:

Walter Frost (615)455-1982

Contract Monitor:

William T. Pennell (509)942-4620

Objective:

To develop the technology for siting wind energy conversion machines relative to small-scale terrain features contained within a region (i.e., a mountain, valley, etc.) selected for wind-energy use.

Program Status:

This was proposed to be a 3 -yr program: the initial 12-mo period began in August 1976 and ended August 1977. The program is presently in its second period.

Progress During Reporting Period:

The manual on siting of wind-turbine generator relative to two-dimensional, small-scale terrain features, written during the first contract period, is now approved for publication. State-of-the-art knowledge of flow over small-scale terrain features has been gathered from various sources and put into an engineering format. The manual outlines procedures for determining the optimum location for a wind turbine relative to a number of small-scale terrain features. The procedures also enable an 
estimate to be made of the loss in available power as a result of displacement of the wind turbine from the optimum location. A manual considering three-dimensional, small-scale terrain features is being prepared. The following work toward this goal is completed:

- Categories of three-dimensional surface features to be analyzed relative to the siting of wind energy conversion machines have been established.

- A literature survey has been completed. Physical models and reported experimental data for flow over isolated three-dimensional surface features and over complex terrain have been compiled and are being interpreted relative to use in siting wind energy conversion machines.

- Analysis of the compiled information has directed special attention to establishing those general flow patterns around three-dimensional features, which will significantly influence wind energy conversion machine sites. These features include zones of accelerated wind, wake patterns and their spatial extent, and vortex location.

Expected Progress During Next Reporting Period:

The final report for the second contract period will be completed. Data on regions of wind-speed enhancement and wake size pertinent to threedimensional, small-scale terrain features will be used as numerical input to the generation of charts and tables and to the development of wind energy conversion machine site evaluation procedures. 
Reports and Publications:

Walter Frost and D. K. Nowak, "Technology Development for Assessment of Small-Scale Terrain Effects on Available Wind Energy." Proceedings of the Third Wind Energy Workshop, Washington, D.C., September 19-21, 1977. 
4.1.10 Revision of Small WECS Handbook (C3b)

Pacific Northwest Laboratory

Richland, WA 99352

Principal Investigator:

Harry L. Wegley (509)942-4627

Objective:

To revise $A$ Siting Handbook For Small Wind Energy Conversion Systems in order to provide the general public with effective, but inexpensive, siting methodologies.

Program Status:

The first revision of the siting handbook is complete. This handbook will be updated as new siting information becomes available.

Progress During Reporting Period:

Historical as well as newly developed siting techniques were reviewed. Appropriate information was incorporated into this siting handbook. The revised handbook was given UC-60 distribution.

Expected Progress During Next Reporting Period: UC-60 distribution of A Siting Handbook For Small Wind Energy Conversion Systems will allow representatives of the small wECS industry and other potential users to review the handbook. Discussions will be held with the American Wind Energy Association. Suggestions from the review of the handbook will be incorporated into a more widely disseminated document. 
Reports and Publications:

H. L. Wegley, M. M. Orgill, and R. L. Drake, A Siting Handbook For Small Wind Energy Conversion Systems. PNL-2521, Battelle, Pacific Northwest Laboratories, Richland, WA 99352, May 1978. 


\subsubsection{Update Large System Siting Handbook (C3c)}

Pacific Northwest Laboratory

Richland, WA 99352

Principal Investigator:

William T. Pennell (509)942-4620

objective:

To provide siting strategies, critical evaluation of available siting techniques and other meteorological information, which can be used to site large WECS or farms of small WECS.

Program Status:

A document entitled A Compendium of Siting Considerations for Large wind Energy Systems has been produced from the old interim siting handbook. The compendium is in draft form and is being revised.

Progress During Reporting Period:

Several requests were received from public utilities for a description of measurement systems that would gather the data needed to evaluate specific locations as WECS sites. In response to these requests, a report describing a measurement program for potential WECS sites was produced. Onsite measurements remain the keystone of any siteselection methodology. Thus, two reports describing a wind-prospecting instrument and the use of such an instrument in siting have also been published.

Expected Progress During Next Reporting Period: The compendium of large WECS siting considerations will be completed. 
Reports and Publications:

P. A. Ekstrom and M. G. Verholek, A Wind

Prospector's Manual. PNL-2514, Battelle, Pacific Northwest Laboratories, Richland, WA 99352, April 1978 .

M. G. Verholek and P. A. Ekstrom, Remote Wind Measurements with a New Microprocessor-Based Accumulator Device. PNL-2515, Battelle, Pacific Northwest Laboratories, Richland, WA 99352, April 1978.

M. G. Verholek, A Measurement Program to Characterize the wind at a Potential WECS Site. PNL-2516, Battelle, Pacific Northwest Laboratories, Richland, WA 99352, March 1978. 


\subsection{WIND CHARACTERISTICS FOR WECS OPERATIONS}

This program area is concerned with the specific windforecasting needs of potential WECS users and the availability and reliability of wind-forecasts for meeting these needs. Electrical dispatchers of utility companies use a daily load forecast to estimate demand and to schedule the mix of powergeneration facilities to meet the predicted demand. Several of these dispatchers have indicated that they would need reliable wind forecasts along with the load forecasts to effectively use the power from WECS on a day-to-day basis.

The consensus among wind forecasters is that no routinely issued forecast products meet the needs of utilities and that little quantitative information exists regarding the reliability of these types of forecasts. Consequently, work began early in FY-1978 to identify the exact types of forecasts needed by utilities and the required accuracies for such forecasts (see Task DI). In addition, efforts were initiated to determine the reliability with which existing wind-forecasting techniques can produce the required forecasts (see Task D2). When these two tasks are completed, current wind-forecasting reliability will be compared with the utilities' requirements. The results of this comparison will determine the direction of future work in this program area. 


\subsection{PROGRESS IN TECHNICAL TASKS}

5.1.1 Identification of Needs and Liaison Activities (DI)

Pacific Northwest Laboratory

Richland, WA 99352

Program Leader:

$$
\text { L. L. Wendell (509)942-4626 }
$$

Objective:

To identify specific wind-forecasting needs of potential WECS users and to determine if current wind-forecasting reliability meets these needs.

Program Status:

This effort was initiated in October 1977 and is proposed to continue through september 1978. If warranted, contract monitoring and coordinating efforts will continue into FY-1979.

Progress During Reporting Period:

Telephone contacts were made with personnel from nine utility companies with inquiries concerning needs and interest in wind forecasting for WECS operations. The contacted personnel were invited to a working-group discussion on this topic, held in Richland, WA, on December 15, 1977. An investigation of current types of available wind forecasts was also begun. Forecast product descriptions were obtained from the National weather Service, Air Weather Service, Global Weather Central, Naval Fleet weather central, and 14 private consulting firms. Invitations to the working-group discussion were extended to all these contacts.

Because of a combination of factors, many people who had expressed interest in attending the 
discussion meeting were unable to attend. The attendees included only one utility representative and four members of the wind-forecasting community. The attendees were briefed on the information, which had been obtained in the telephone conversations with those who did not attend the meeting. Three main points resulted from the discussions:

1. Wind forecasting would probably be valuable in the same sense as load forecasting; that is, in the area of planning for the use of various generation equipment to meet the upcoming demands for the power. Work on establishing forecast reliability for 24 to $36 \mathrm{hr}$ is needed to determine if it is at least as reliable as the load forecasting.

2. Wind forecasting for hour-by-hour load following could be of great value. However, since there is little margin for error, current windforecasting reliability may make this an unrealistic goal.

3. Comprehensive information on wind-forecasting reliability is very meager and certainly inadequate to evaluate the potential of windpower forecasting.

Expected Progress During Next Reporting Period:

The working-group discussions indicated that the types of forecasts required by utilities and acceptable limits of reliability for each type of forecast should be carefully established, using both information gathered in the discussions and from continued liaison with utilities. 
close contact will be maintained with the utility at Clayton, New Mexico, because their needs arise from the actual experience of operating a wind turbine.

Prior to this time the possible wind-forecasting needs of small WECS users have not been considered. Since some applications of small wECS may benefit from a wind forecast, a sampling of the needs of the users of small machines will be obtained. These needs will be factored into the recommendations for further work.

Reports and Publications:

L. L. Wendell, H. L. Wegley, and M. G. Verholek, Report from a Working Group Meeting on wind ForeCasts for WECS Operation. PNL-2513, Battelle, Pacific Northwest Laboratories, Richland, WA 99352, March 1978. 


\section{1 .2 Determination of Wind-Forecasting Uncertainty (D2)}

Pacific Northwest Laboratory

Richland, WA 99352

Principal Investigator:

Harry L. Wegley (509)942-4627

Objective:

To determine the availability and reliability of existing wind-forecasting techniques to meet the needs of potential WECS users.

Program Status:

This program began in October 1977 and will continue through september 1980.

Progress During Reporting Period:

system planners and electrical dispatchers from nine utilities in various regions of the United States were contacted to determine windforecasting requirements for efficient WECS use. A working-group discussion on wind forecasts for WECS operations was held on December 15, 1977, in Richland, WA. From contacts with utilities as well as the group discussions, it was concluded that a 24-hr forecast of hourly mean wind speeds would best serve the needs of utilities. However, a survey of available wind forecasts revealed that this type of forecast is neither routinely produced nor verified. Consequently, a decision was made to obtain such forecasts for a reliability study. In March an evaluation panel met and began work on a request for proposals. In addition, wind data from three candidate wind-turbine sites were ordered for the wind-forecast verification studies. 
Expected Progress During Next Reporting Period:

Contracts for production of the wind forecasts by various existing techniques will be awarded early in FY-1979. Contract work will be completed and a topical report issued on the wind-forecast verification studies by late FY-1979. At that time a decision will be made on whether or not to broaden the verification studies.

Reports and Publications:

None. 


\subsection{REFERENCES}

1. Federal Wind Energy Program, Program Summary, January 1978, DOE/ET-002311, DOE Division of Solar Technology, Superintendent of Documents, U.S. Government Printing office, Washington, D.C. 20402. Stock No. 061-000-00050-0.

2. Summary of the Development Plan for the Wind Characteristics Program Element of the Federal wind Energy Program.

PNL-2501, Pacific Northwest Laboratory, Richland, WA 99352, February 1978 . 

APPENDIX A

PUBLISHED REPORTS

GIVEN UC-60 DISTRIBUTION 


\title{
WIND CHARACTERISTICS PROGRAM ELEMENT (WCPE)
}

\author{
Reports given UC-60 distribution and available from: \\ National Technical Information Service \\ United States Department of Commerce \\ 5285 Port Royal Road \\ Springfield, Virginia 22151
}

Price: Printed Copy, * Microfiche $\$ 3.00$

\begin{tabular}{|c|c|}
\hline ^Pages & $\begin{array}{c}\text { NTIS } \\
\text { Selling Price }\end{array}$ \\
\hline $001-025$ & $\$ 4.50$ \\
\hline $026-050$ & 5.00 \\
\hline $051-075$ & 5.50 \\
\hline $076-100$ & 6.00 \\
\hline $101-125$ & 6.50 \\
\hline $126-150$ & 7.00 \\
\hline $151-175$ & 7.78 \\
\hline $176-200$ & 8.50 \\
\hline $201-225$ & 8.75 \\
\hline $226-250$ & 9.00 \\
\hline $251-275$ & 10.00 \\
\hline $276-300$ & 10.25 \\
\hline
\end{tabular}

The WCPE is coordinated for DOE/Wind Systems Branch by Pacific Northwest Laboratory, Richland, WA 99352. The attached listing has been prepared by:

Pam R. Partch

WCPE Reports Schedule and Control Coordinator

Phone: FTS 444-4410

Commercial: (509) 942-4410 
Author

Wentink, T., Jr.

Wentink, T., Jr.

Freeman, B. E.

Freeman, B. E

Meroney, R. N. et al.

Justus, C. G. et a 1 .

Justus, C. G. et a 1

Corotis, R. B.

Meroney, R. N. et al. Wind Tunnel Simulation of the Influence of Two-Dimensional Ridges on Wind Speed and Turbulence--Tabulated Experimental

Freeman, B. E. et al. Development of a Wind Energy Site Selection Methodology

Elderkin, C. E.

Semi-Annual Report of the Wind Characteristics Program Element for the Period

Wind Power Potential of Alaska: Part I, Sites

Study of Alaskan Wind Power and Its

\section{Mathematical Modeling of Topographic}

A New Wind Energy Site Selection Me thodology

Sower Installations: Wind Tunnel Simulation of the Influence and Turbulence

Wind Energy Statistics for Large Arrays Central U.S Regions)

Reference Wind Speed Distributions and and Performance Evaluation Applications

Wind Power Potential of Alaska: Part II ind Duration Curve Fits and Output

Stochastic Modelling of Site Wind
Document No.

NSF/RANN Grant GI-43098

NSF/RANN/SE/AER74-00239/FR-76/1

BNWL-SA-5935

SAI76-614-LJ (NSF Grant)

RDA/NSF / 00702-75/1

RDA/NSF $-00547 / 76 / 1$

$0 R 0 / 5108-76 / 4$

RL0/2229-T12-76/1

ERDA/NSF - 00357/76/1

$\mathrm{RL} 0 / 2438-76 / 1$

RL $0 / 2440-76 / 4$

BNWLL-2220 WI ND-2
Affiliation \& Address

Geophysical Institute

Fairbanks, AK 99701

University of Alaska

Geophysical Institute

Science Applications, Inc.

P. O. Box 2351

ience Applications, Inc

P. 0. Box 2351

La Jolla, CA 92037

Colorado State University

Dept. of Civil Engineerin

Georgia Institute of Technolagy

School of Aerospace Engineering Atlanta, GA 30332

Georgia Institute of Technology School of Aerospace Engineering Atlanta, GA 30332

University of Alaska

Geophysical Institute

Fairbanks, Ak ggior

Dept. Of Civil Engineering

Evanston,

Colorado State University Department of Civil Engineering Fort Collins, CO 80523

Science Applications, Inc.

. O. Box 2351

a Jolla, CA 92037

Pacific Northwest Laboratory

Richland, WA 99352
No. of

Date

August 1974

134

February 1976

181

April 1976 Micro-

May 1976 (SAI) 233

Ju1y 1976

August 1976

August 1976

November 1976

December 1976

December 1976

January 1977 
Elderkin, C. E.

AWEA

Vukovich, F. M.
Clayton, C. A.

Elderkin, C:.
Wendell, L. L.

Garstang, M. et al.

Garstang, M. et a 1 .

Verholek, M. G.

Ramsdel1, J. V.

Wendel I, L. L. Wegley, H. L.
Verholek, M. G.

Ekstrom, P. A.

Verholek, M. G.

Verholek, M. G

Verholek, M. G.

Wegley, H. L.
Summary of the Development Plan for the wind Characteristics Program Element of Federal Wind Energy Program

Survey of Historical and Current Site Selection Techniques for the Placement

On a Technique to Determine Wind

Statistics in Remote Locations

Semi-Annual Report of the Wind Character istics Program Element for the Period

Coastal Zone Wind Energy

Part I - Synthesis and Results

Coastal Zone Wind Energy

Part II - Cl imatology

PNL-250

BNWL-2220 WIND-9

RL $0-2445-78 / 1$

PNL -2519

$R\llcorner 0-2344-76 / 77-5$

RL0-2344-76/77-6

PNL -2516

A Measurement Program to Characterize

the Wind at a Potential WECS Site

Estimates of the Number of Large

Ampli tude Gusts

Report from a Working Group Meeting on wind Forecasts for WECS Operation

A Wind Prospector's Instrument

Remote Wind Measurements with a New Microprocessor-Based Accumulator Device

PNL-2515

Preliminary Results of a Field Experiment to Characterize Wind Flow Through a Vertical Plane

A Siting Handbook for Smiall Wind Energy Conversion Systems

\begin{tabular}{|c|c|}
\hline $\begin{array}{l}\text { Pacific Northwest Laboratory } \\
\text { P. O. Box } 999 \\
\text { Richland, WA } 99352\end{array}$ & October 1977 \\
\hline $\begin{array}{l}\text { American Wind Energy Association } \\
\text { c/o Windworks } \\
\text { P. 0. Box } 329 \text {, Route } 3 \\
\text { Mukwonago, WI } 53149\end{array}$ & December 1977 \\
\hline $\begin{array}{l}\text { Research Triangle Institute } \\
\text { P. O. Box } 12194 \\
\text { Research Triangle Park, NC } 27709\end{array}$ & December 1977 \\
\hline $\begin{array}{l}\text { Pacific Northwest Laboratory } \\
\text { P. O. Box } 999 \\
\text { Richland, WA } 99352\end{array}$ & January 1978 \\
\hline $\begin{array}{l}\text { University of Virginia } \\
\text { Clark Hall } \\
\text { Charlottesville, VA } 22903\end{array}$ & January 1978 \\
\hline $\begin{array}{l}\text { University of Virginia } \\
\text { Clark Hall } \\
\text { Charlottesville, VA } 22903\end{array}$ & $\begin{array}{l}\text { January } 1978 \\
\text { (in printing) }\end{array}$ \\
\hline $\begin{array}{l}\text { Pacific Nor thwest Laboratory } \\
\text { P. O. Box } 999 \\
\text { Richland, WA } 99352\end{array}$ & March 1978 \\
\hline $\begin{array}{l}\text { Pacific Nor thwest Laboratory } \\
\text { P. O. Box } 999 \\
\text { Richland, WA } 99352\end{array}$ & March 1978 \\
\hline $\begin{array}{l}\text { Pacific Northwest Laboratory } \\
\text { P. O. Box } 999 \\
\text { Richiand, WA } 99352\end{array}$ & March 1978 \\
\hline $\begin{array}{l}\text { Pacific Nor thwest Laboratory } \\
\text { P. O. Box } 999 \\
\text { Richland, WA } 99352\end{array}$ & Apri1 1978 \\
\hline $\begin{array}{l}\text { Pacific Northwest Laboratory } \\
\text { P. 0. Box } 999 \\
\text { Richiand, WA } 99352\end{array}$ & April 1978 \\
\hline $\begin{array}{l}\text { Pacific Northwest Laboratory } \\
\text { P. O. Box } 999 \\
\text { Richland, WA } 99352\end{array}$ & April 1978 \\
\hline $\begin{array}{l}\text { Pacific Nor thwest Laboratory } \\
\text { P. O. Box } 999 \\
\text { Richland, WA } 99352\end{array}$ & May 1978 \\
\hline
\end{tabular}




\begin{tabular}{|c|c|c|}
\hline Verholek, H. G. & $\begin{array}{l}\text { Summary of Wind Data from Nuclear Power } \\
\text { Plant Sites }\end{array}$ & BNWL-2220 WI ND-4 \\
\hline Orgill, M. M. & Survey of Wind Measurement Field Programs & BNWL-2220 WIND-3 \\
\hline Justus, C. G. et al. & $\begin{array}{l}\text { Wind Energy Statistics for Large Arrays } \\
\text { of Wind Turbines (Great Lakes and } \\
\text { Pacific Coast Regions) }\end{array}$ & RL.0/2439-77/2 \\
\hline Dochon, C. E. & $\begin{array}{l}\text { Measurement and Analysis of Wind Flow in } \\
\text { Complex Terrain with Application to Siting } \\
\text { of WECS }\end{array}$ & ERDA/NSF $-00619 / 75 / 1$ \\
\hline Traci, R. M. et al. & $\begin{array}{l}\text { Development of a Wind Energy Site } \\
\text { Selection Methodology }\end{array}$ & RL0/2440-77/11 \\
\hline Hewson, E. W. et al. & $\begin{array}{l}\text { Vegetation as an Indicator of High wind } \\
\text { Velocity }\end{array}$ & RL $0-2227-T 24-77 / 2$ \\
\hline Elliot, D. L. & $\begin{array}{l}\text { Synthes is of National wind Energy } \\
\text { Assessments }\end{array}$ & BNWL -2220 WIND -5 \\
\hline $\begin{array}{l}\text { Elderkin, C. E. } \\
\text { Ramsdell, J. V. }\end{array}$ & $\begin{array}{l}\text { Annual Report of the Wind Characteristics } \\
\text { Program Element for the Period April } 1976 \\
\text { Through June } 1977\end{array}$ & BNWL -2220 WIND-10 \\
\hline $\begin{array}{l}\text { Changery, M. J. } \\
\text { Hodge, W. T. } \\
\text { Ramsdell, J. V. (PNL) }\end{array}$ & Index - Summarized Wind Data & BNWL-2220 WIND- 11 \\
\hline Corotis, R. B. & $\begin{array}{l}\text { Stochastic Modeling of site Wind } \\
\text { Characteristics }\end{array}$ & RL $0 / 2342-77 / 2$ \\
\hline Cliff, W. C. & $\begin{array}{l}\text { The Effect of Generalized Wind Character- } \\
\text { istics on Annual Power Estimates from } \\
\text { Wind Turbine Generators }\end{array}$ & $P N L=2436$ \\
\hline Doran, J. C. et al. & Accuracy of Wind Power Estimates & PNL-2442 \\
\hline
\end{tabular}

Pacific Northwest Laboratory
P. O. Box 999
Richland, WA 99352
Pacific Northwest Laboratory
P. O. Box 999
Richland, WA 99352
Georgia Institute of Technology
School of Aerospace Engineering
Atlanta, GA 30332
University of Oklahoma
School of Meteorology
Norman, OK 73019
Science Applications, Inc.
P. O. Box 2351
La Jolla, CA 92038
Oregon State University
Department of Environmental
Sciences
Corvallis, OR 97331


Cliff, W. C.
Justus, C. G.

Elderkin, C. E.

Cliff, W. C.
Fichti, G. H.

Marrs, R. W.

Kerrigan, T. C.

Kerrigan, T. C.

Kerrigan, T. C.
Simulation of Hourly wind Speeds for Randomly Dispersed Sites

Wind Velocity-Change (Gust Rise) Criteria for Wind Turbine Design

Regions of the Continental United States Susceptible to Eolian Action

A Technique for Analyzing the Structure

of Atmospheric Turbulence

A Verification Statistic for Numerical Wind Models

Spectral Estimates of a Hind Fluctuation Statistics Pertaining to Wind Energy
Generators

PNL -2523

PNL - 2526

RL0-2343-78/2

PNL -2500

PNL -2510

\begin{tabular}{|c|c|}
\hline $\begin{array}{l}\text { Pacific Northwest Laboratory } \\
\text { P. O. Box } 999 \\
\text { Richiand, WA } 99352\end{array}$ & May 1978 \\
\hline $\begin{array}{l}\text { Pacific Northwest Laboratory } \\
\text { P. 0. Box } 999 \\
\text { Richiand, WA } 99352\end{array}$ & July 1978 \\
\hline $\begin{array}{l}\text { University of Wyoming } \\
\text { Laramie, WY } 82071\end{array}$ & $\begin{array}{l}\text { July } 1978 \\
\text { (in printing) }\end{array}$ \\
\hline $\begin{array}{l}\text { Pacific Northwest Laboratory } \\
\text { P. 0. Box } 999 \\
\text { Richiand, WA } 99352\end{array}$ & September 1978 \\
\hline $\begin{array}{l}\text { Pacific Northwest Laboratory } \\
\text { P. O. Box } 999 \\
\text { Richiand, WA } 99352\end{array}$ & September 1978 \\
\hline $\begin{array}{l}\text { Pacific Northwest Laboratory } \\
\text { P. O. Box } 999 \\
\text { Richiand, WA } 99352\end{array}$ & September 1978 \\
\hline
\end{tabular}

Pacific Northwest Laboratory .

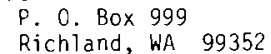

\section{.}

,

3

25


. 
No. of

Copies

\section{OFFSITE}

A. A. Churm

DOE Chicago Patent Group

9800 South Cass Avenue

Argonne, IL 60439

C. I. Aspliden

Department of Energy

600 E Street N.W.

Washington, DC 20545

G. P. Tennyson

Department of Energy

600 E Street, N. W.

Washington, DC 20545

\section{DOE Technical Information Center}

Thomas Vonier

AWEA Windletter

2222 Q Street, N. W.

Washington, DC 20008

Dr. Paul B. Maccready, Jr.

Aerovironment, Inc.

145 Vista Avenue

Pasadena, CA 91107

Clarissa Quinlan

Alaska State Energy Office

338 Denali Street

Anchorage, AK 99501

Paul N. Vosburgh

Alcoa Allied Products

Aluminum Company of America

Alcoa Center, PA 15069

Dr. K. C. Spengler

American Meteorological Society

45 Beacon Street

Boston, MA 02108
Ben Wolff

American Wind Energy Association

1000 Connecticut Avenue, N. W.

Suite 1111

Washington, DC 20036

Richard Katzenberg

American Wind Energy Association

Natural Power, Inc.

New Boston, NH 03070

E. J. Warchol

Bonneville Power Administration

P. 0. Box 3621

Portland, OR 97208

S. J. Hightower

Bureau of Reclamation

Denver Federal Center

Building 67, Code 254

Denver, C0 80225

M. Ginosar

California Solar Energy Commission

Energy Resources, Conservation and Development Commission

1111 Howe Avenue, Mai1 Stop 15

Sacramento, CA 95825

Robert Ball

Center for the Environment and

Man, Inc.

275 Windsor Street

Hartford, CT 06120

Lawrence W. Hallanger

Civil Engineering Laboratory, NCBC Port Hueneme, CA 93043

Dr. R. J. Hawks

Clarkson College

Potsdam, NY 13676 
No. of

Copies

Dr. R. N. Meroney

Colorado State University

Fort Collins, CO 80523

E. H. Gilmore

Department of Agriculture

Agriculture Research Service

Bushland, TX 79012

L. A. Liljedah 1

Department of Agriculture

Agriculture Wind Energy Program

Building 001, Room 126 BARC-West

Beltsville, MD 20705

Douglas G. Fox

Department of Agriculture

Forest and Mountain Meteorology

Rocky Mountain Forest and Range

Experiment Station

240 West Prospect Street

Fort Collins, CO 80521

Jay Tappan

Department of Energy

State of Oregon

Labor and Industries Building

Room 111

Salem, OR 97310

Harry Moses

Department of Energy

Division of Biomedical and

Environmental Research

Mail Stop E-201

Washington, DC 20545

Major T. E. Kullgren

DFCEM

USAF Academy, CO 80840

Carl Miner TAN-604

EG\&G Idaho, Inc.

P. 0. Box 1625

Idaho Falls, ID 83401
No. of

Copies

Dr. Edgar Demeo

Electric Power Research Institute

3412 Hillview Avenue

Palo Alto, CA 94303

Jim Lerner

Energy Resources Conservation and Development Commission

California Solar Energy Office

Mail Stop 15

Sacramento, CA 95825

Dr. 01le Ljungstrom

FFA, The Aeronautical Research Institute

Forskningsstationen i stockholm

Drottning Kristinas Vaỹ 47

S-114 28 Stockholm, Sweden

R. B. Lawford

Fisheries \& Environment

25 St. Clair Ave. East

Toronto, Canada M4T IM2

Dr. W. Frost

FWG Associates, Inc.

R. R. 3, Box 331

Tullahoma, TN 37388

L. Krawitz

General Electric Company

P. 0. Box 8555

Philadelphia, PA 19101

R. C. Koch

Geomet, Inc.

15 Firstfield Road

Gaithersburg, MD 20760

C. G. Justus

Georgia Institute of Technology

Atlanta, GA 30332

J. Park

HELION, Inc.

Box 445

Brownsville, CA 95919 
No. of

Copies

Dr. T. R. Kornreich

JBF Scientific Corporation

1925 North Lynn Street

Suite 308

Arlington, VA 22209

Dr. J. B. Knox

Lawrence Livermore Laboratory

University of California

P. 0. Box 808

Livermore, CA 94550

Ms. Abbey Page

Maine Office of Energy Resources

55 Capitol

Augusta, ME 04330

S. M. Howard

Meteorology Research, Inc.

P. 0. Box 637

Altadena, CA 91001

Frank R. Eldrige, Jr.

MITRE Corporation

1820 Dolley Madison Boulevard

McLean, VA 22102

V. F. Garrett

Montana Energy and MHD Res. and

Dev. Inst., Inc.P. 0. Box 3809

Butte, MT 59701

J. Konigsberg

Montana Energy Office

Capital Station

Helena, MT 59601

Phillip French

NASA Scientific and Technical Information Facility

P. 0. Box 8757

Baltimore/Washington International Airport

MD 21240
No. of

Copies

R. A. Wolt
NASA Scientific and Technical

Mai1 Stop 500-201

Cleveland, $\mathrm{OH} 44135$

M. J. Changery

National Oceanic and Atmospheric Administration

National Climatic Center

Federal Building

Asheville, NC 28801

R. J. Templin

National Research Council of Cânada

National Aeronautical Establishment

M-2 Montreal Road

Ottawa, Ontario KIA or 6

Ms. Peggy McDonald

N. E. Solar Energy Center

70 Memorial Drive

Cambridge, MA 02142

John L. Zimmerman

New England Wind Energy

Conversion Services

RDL Box 52E

Moretown, Vermont 05660

P. W. Blakeley

New Zealand Electricity

Rutherford House

Lambton Quay

Wellington, New Zealand

M. W. Edelstein

North American Weather Consultants

600 Norman Firestone Road

Goleta, CA 93017

R. B. Corotis

Civil Engineering - Tech. Northwestern University

Evanston, IL 60201 
E. W. Hewson/J. E. Wade Oregon State University Corval1is, OR 97331

R. de Violini

Pacific Missile Test Center CODE 3250-3

Point Mugu, CA 93042

S. C. Crow

Poseidon Research

11777 San Vincente Blvd.

Suite 641

Los Angeles, CA 90049

D. Tompkins

PRC Eng. Analysis Co.

7600 01d House Road

McLean, VA 22102

Dr. F. M. Vukovich

Research Triangle Institute

P. 0. Box 12194

Research Triangle Park, NC 27709

Terry J. Healy

Rockwell International

Rocky Flats Plant

P. 0. Box 464

Golden, CO 80401

J. W. Reed

Sandia Laboratories

Division 5443

P.0. Box 5800

A1buquerque, NM 87115

R. M. Traci

Science Applications, Inc.

P. 0. Box 2351

La Jolla, CA 92038

D. M. Hardy

Solar Energy Research Institute

1536 Cole Blvd.

Golden, C0 80401
Dr. C. M. Bhumralkar

Stanford Research

Institute, Internationa 1

Men1o Park, CA 94025

Marcel R. Harper

Tetra Tech. Inc.

1811 Fort Myer Drive

Arlington, VA 22209

C. Jump

US Army Corps of Engineers

Seattle District

P. 0. Box C 3755

Seattle, WA 98124

Bruce Bailey

Atmospheric Sciences Research Center

SUNY Albany - ES 324

Albany, NY 12222

R. Crowder

Taylor Woodrow Construction, Limited

Taywood House

345 Ruislip Road

Southa 11

Middlesex UBI $2 Q \mathrm{X}$

England

Dr. T. Wentink, Jr.

University of Alaska

Fairbanks, AK 99701

Dr. P. Yuen

University of Hawai at Manoa

Holmes Hall 240

2540 Dole Street

Honolulu, HI 96822

C. E. Duchon

University of OKlahoma

200 Felgar Street

Norman, OK 73069 
No. of

Copies

Dr. N. K. Wagner

Dept. of Civil Engineering

University of Texas

Austin, TX 78712

Dr. M. Garstang

University of Virginia

Charlottesville, VA 22903

Dr. R. W. Marrs

University of Wyoming

Laramie, WY 82071

R. E. Akins

Department of Engineering and Mechanics

Virginia Polytech Institute

Blacksburg, VA 24069

David Kapus

Washington State Division of

Engineering and Architecture 106 Maple Drive

01 ympia, WA 98504

Ms. Susan Hosch

Washington State Energy Office

$400 \mathrm{E}$. Union Avenue, ist Floor

01 ympia, WA 98504

R. K. Woodruff

Washington Public Power Supply System

P. 0. Cox 968

Richland, WA 99352

S. R. Epur

Wichita State University

P. 0. Box 44

Wichita, KS 67208

Farrell Smith Seiler

Wind Energy Report

Box 14 - 104 X. Village Avenue

Rockville Centre, NY 11571
No. of

Copies

ONS ITE

2 DOE Richland Operations Office

P. 0. Box 550

Richland, WA 99352

R. K. Stewart

H. E. Ransom

37 Pacific Northwest Laboratory

Battelle Boulevard

Richland, WA 99352

W. R. Barchet

R. L. Conley

J. R. Connel 1

J. C. Doran

R. L. Drake

C. E. Elderkin (10)

D. L. Elliot

T. R. Hiester

P. R. Partch

W. T. Pennel 1

E. H. Phinney

D. C. Powell

J. V. Ramsde 11

D. S. Renne

C. L. Simpson

H. L. Wegley

L. L. Wendel 1 (5)

Technical Information - Library (5)

Publishing Coordination (2) 
